\title{
Fiscal deficit sustainability of the Spanish regions
}

\author{
Josep Lluís Carrion-i-Silvestre
}

AQR-IREA research group

Department of Econometrics, Statistics and Spanish Economy

University of Barcelona

Av. Diagonal, 690, 08034 Barcelona.

Tel: 934024598, Fax: 934021821

Email: carrion@ub.edu

May 8, 2015 


\begin{abstract}
The fiscal deficit of the Spanish Autonomous Communities (ACs) is investigated using nonstationary panel data analysis. The paper considers the two main approaches in the literature, first assessing whether there is a long-run relationship between the revenues and expenditures of the ACs and second focusing on the use of fiscal rules. The paper shows that it is possible to relate these approaches in a unified framework.
\end{abstract}

JEL Classification: E62, H62, C12, C22

Keywords: Fiscal deficit, fiscal rules, panel data, cross-section dependence, common factors 


\section{Introduction}

The sustainability of government fiscal policy is a major issue, especially in the current context in which developed economies are facing the effects of the global crisis. Efforts to contain public spending and streamlining the provision of public goods is an objective of present governments trying to reactivate economies in an environment in which there is difficulty in finding funding and liquidity. Borrowers monitor governments' accounts when deciding where to locate their investment and loans. In this scenario, Spain is a case of relevant interest, given the adjustment procedures that have been implemented to reduce the level of debt and the pressure of the fiscal deficit on the Spanish economy. It is also of interest in that since the beginning of the democratic period in 1978, Spain has started a process of transferring competences to the Spanish regions, or autonomous communities (ACs), which involves the transferral of certain taxes and the provision of public services - essentially, security, health and education. This decentralized fiscal position has led the central government to monitor the ACs when trying to reduce the excessive deficit and debt levels of the Spanish economy.

The aim of this paper is to analyse the sustainability of the fiscal policy of the ACs as a whole using the two approaches that have mainly been adopted in the literature. The concept of sustainability of fiscal policy implies the fulfilment of the so-called intertemporal budget constraint, which states that the current level of debt in an economy should equal the present value of future fiscal surpluses. If this condition is to be met, economies cannot indefinitely issue debt to cover fiscal deficits as the markets will observe a risk of bankruptcy. To test whether this condition is satisfied, two different relationships are analysed. First, the study uses panel data cointegration techniques to assess whether there is a long-run relationship between the revenues and expenditures. Second, it investigates if the fiscal rule that relates the fiscal primary surplus and debt levels holds for the Spanish ACs.

The information available for conducting the study covers the period 1984-2012, thus defining series on the fiscal variables of revenues, expenditures and debt over a relatively short time period. ${ }^{1}$ This suggests that the analysis of fiscal deficit sustainability should be based on the use of panel data techniques to combine information for both temporal and cross-sectional dimensions. The analysis should also take into account that the fiscal variables used here show a high degree of persistence, i.e. they can be I(1) non-stationary variables. In line with this, econometric techniques that consider this feature should be applied if meaningful conclusions are to be obtained. The paper discusses the different alternatives that exist in the literature when specifying models that will allow the assessment of the sustainability of fiscal deficit and the (necessary and sufficient) conditions that must be fulfilled. As discussed in the following sections, there are methodological positions that may seem contradictory, although this paper shows the connecting links among them.

The paper is structured as follows. Section 2 provides a review of selected literature on fiscal sustainability. Section 3 develops the arithmetic of debt and its relation to the fiscal deficit, explaining the conditions of fiscal deficit sustainability. Section 4 presents fiscal rules as an alternative way of assessing fiscal deficit sustainability. Section 5 describes the database. Section 6 details the econometric methodology and the results of its application. Finally, Section 7 concludes. All tables and figures appear in the on-line companion appendix.

\footnotetext{
${ }^{1}$ It should be borne in mind that the territorial organization of the Spanish ACs was implemented in 1984, so there is no previous information concerning this level of government.
} 


\section{Review of the literature}

The contributions in the literature can broadly be classified into two groups. First, there are the analyses based on a univariate approach, which study the order of integration of the deficit (including interest payments on debt) (see HAMILTON and FLAVIN, 1986) or the stock of public debt (see WILCOX, 1989). Second, there are studies that are based on a multivariate approach, examining if there is a long-run relationship between the flows of revenues and expenditures (see, for example, TREHAN and WALSH, 1988; HAKKIO and RUSH, 1991; HAUG, 1991; QUINTOS, 1995; MARTIN, 2000). Aiming to reconcile both approaches, TREHAN and WALSH (1991) derive sufficient conditions for fiscal sustainability, which require (i) that there is a cointegrating relationship between the primary deficit and debt and (ii) that the quasi-difference of the primary deficit is an $\mathrm{I}(0)$ stationary process.

These early studies focused mainly on US fiscal sustainability. Other subsequent studies have refined the analysis by incorporating the possibility of different economic systems (structural changes) that are associated with different degrees of sustainability (see, for example, QUINTOS, 1995; MARTIN, 2000; AFONSO, 2005) and have also generalized the definition of sustainability to distinguish between strict and weak sustainability (see the discussion below). AFONSO (2005) provides a comprehensive summary of empirical studies in the literature.

BOHN (1998) criticizes these analyses, arguing that, in principle, any order of integration of the public debt is consistent with the fulfilment of the intertemporal budget constraint. BOHN $(1998,2007)$ offers an alternative way of assessing the sustainability of the public deficit, a proposal that is based on the specification of a fiscal rule measuring the reaction of the primary surplus to variations in the level of debt. Thus, a (statistically significant) positive response of the primary surplus to changes in debt would constitute a sufficient condition for the sustainability of fiscal policy. According to BOHN (2007), the relationship between the primary deficit and debt is of economic interest and goes beyond establishing whether or not there is a cointegrating relationship between the fiscal variables. However, QUINTOS (1995) shows that the assessment of the order of integration of the public debt is still relevant, provided that it gives information on the degree of sustainability (strong or weak) of fiscal deficit.

The encouraging point of BOHN's (2007) criticism lies in trying to find significant relationships between the primary deficit and debt. However, it should be borne in mind that the estimation and statistical inference analyses that he proposes require assessing the order of integration of the variables involved in the relationship if misleading conclusions are to be avoided. It is well known that the consistence of the estimated parameters of the models that relate $\mathrm{I}(1)$ non-stationary variables depends on whether cointegration exists. Consequently, as a preliminary step in estimating the models advocated by BOHN $(1998,2007)$, it is necessary to assess the order of integration of the fiscal variables, given the risk of facing a spurious relationship if the variables in the model are I(1) non-stationary stochastic processes.

The two methodological approaches discussed so far have also been applied in a regional environment. On the one hand, WESTERLUND et al. (2011) analyse the relationship between the revenues and expenditures - at the state and local government levels for the US - using panel data cointegration techniques. On the other hand, ESTELLER and SOLÉ (2004) applied the BOHN's (1998) methodology to analyse the sustainability of the fiscal policy of Spanish ACs, but without considering the non-stationarity of the variables. As can be seen, the empirical evidence on fiscal sustainability at the regional level is scarce and mostly concentrated in the US economy. The analysis that is conducted in this paper is interesting as it increases empirical evidence focusing on the Spanish ACs, where the decentralization system and fiscal sustainability are hot political topics at present. The approach that is adopted in this paper uses procedures designed to work 
with non-stationary panel data, a strategy that has not yet been implemented in the case of the Spanish regions.

Finally, it should be mentioned that the estimated specifications in the papers mentioned above are heterogeneous in terms of the definition of the variables involved in the analysis. There are studies that use fiscal variables in nominal terms, or in real terms relative to GDP or to the population. BOHN $(2005,2007)$ indicates that this is not important as long as the discount factor is measured adequately. In our case, the variables are used in levels and expressed in real terms.

\section{The arithmetic of debt and fiscal sustainability}

The government budget constraint for each period can be written as:

$$
\Delta B_{t}=G_{t}-R_{t}=D E F_{t}
$$

where $B_{t}$ is the market value of government debt in real terms, $G_{t}$ is the government spending in real terms, including interest payments, $R_{t}$ represents the revenues in real terms, and $\Delta$ is the difference operator. The deficit $\left(D E F_{t}\right)$ is the difference between government revenues and expenditures of a time period, a variable that by definition equals the change in the debt. If $i_{t}$ denotes the real interest rate $^{2}$ and assuming that this variable is $\mathrm{I}(0)$ stationary around a mean value $i$ (see HAKKIO and RUSH, 1991), it is possible to define:

$$
G_{t}=G E_{t}+i_{t} B_{t-1}
$$

where $G E_{t}$ is the actual expenditure, excluding interest payments, and the second term of the right side of equation (2) represents the payment of interest on the accumulated debt at the end of the previous period. Note that the debt can be expressed as:

$$
B_{t}=(1+i) B_{t-1}+E X P_{t}-R_{t},
$$

where $E X P_{t}=G E_{t}+\left(i_{t}-i\right) B_{t-1}$ or alternatively, $B_{t}=(1 /(1+i))\left(R_{t+1}-E X P_{t+1}\right)+(1 /(1+i))$ $B_{t+1}$. As the government is subject to the same budget constraint in $t+1, t+2$, and so on, the budgetary constraints of each period can be intertemporally added and obtain:

$$
B_{t}=\sum_{j=0}^{\infty}\left(\frac{1}{(1+i)}\right)^{j+1}\left(R_{t+j+1}-E X P_{t+j+1}\right)+\lim _{j \rightarrow \infty}\left(\frac{1}{(1+i)}\right)^{j+1} B_{t+j+1}
$$

The intertemporal budget balance occurs if and only if the present value of government debt equals the present value of future budget surpluses,

$$
B_{t}=\sum_{j=0}^{\infty}\left(\frac{1}{(1+i)}\right)^{j+1}\left(R_{t+j+1}-E X P_{t+j+1}\right)
$$

i.e. if and only if the transversality condition holds:

$$
E_{t}\left(\lim _{j \rightarrow \infty}\left(\frac{1}{(1+i)}\right)^{j+1} B_{t+j+1}\right)=0
$$

\footnotetext{
${ }^{2}$ Note that the variables could be expressed in nominal terms or as a ratio of real GDP. If the variables are in nominal terms, $i_{t}$ is the nominal interest rate. If the variables are expressed in real terms, $i_{t}$ is the real interest rate. Finally, if the variables are expressed as a ratio of GDP, $1+i_{t}$ would be the interest rate adjusted by the growth rate of the economy, which is obtained by dividing the nominal growth rate of the GDP.
} 
where $E_{t}(\cdot)$ denotes the conditional expectation on the information set available at time $t$. If the condition given by equation (5) is satisfied, then the deficit is sustainable, given that the stock of debt that remains in the hands of the economic agents will grow at a slower rate on average than the growth rate of the economy (approximated by the real interest rate). Therefore, this implies that the government is not financing its deficit by issuing new debt following a Ponzi scheme game. To implement the empirical testing of fiscal sustainability, the first difference in equation (3) is taken to obtain:

$$
\Delta B_{t}=G_{t}-R_{t}=\sum_{j=0}^{\infty}\left(\frac{1}{(1+i)}\right)^{j+1}\left(\Delta R_{t+j+1}-\Delta E X P_{t+j+1}\right)+\lim _{j \rightarrow \infty}\left(\frac{1}{(1+i)}\right)^{j+1} \Delta B_{t+j+1}
$$

so that sustainability is associated with the transversality condition:

$$
E_{t}\left(\lim _{j \rightarrow \infty}\left(\frac{1}{(1+i)}\right)^{j+1} \Delta B_{t+j+1}\right)=0 .
$$

If the condition given by equation (7) is satisfied, it can be concluded that there is an intertemporal budget balance (deficit sustainability) because this would imply that the government would incur a future surplus that is equal in expected value to the market value of the debt.

The empirical literature has followed two different approaches when assessing the sustainability of fiscal deficit. One group of studies - the univariate-based approach - has concentrated on analysing the stochastic properties of $B_{t}$ (see HAMILTON and FLAVIN,1986; WILCOX, 1989). In this case, fiscal deficit sustainability would require $\Delta B_{t}$ to be $\mathrm{I}(0)$ stationary, i.e. a condition that is equivalent to checking whether the I(1) non-stationary vector of variables $\left(G_{t}, R_{t}\right)$ are cointegrated with the cointegration vector $(1,-1)^{\prime}$. A second group of studies - the multivariate-based approach - analyses whether the vector of variables $\left(G_{t}, R_{t}\right)$ generate a cointegrating relationship, assuming that the cointegration vector is known and equal to $(1,-1)^{\prime}$; in this case, this result in the approach of the first group of studies - or estimating the cointegration vector (see TREHAN and WALSH, 1988, 1991; HAKKIO and RUSH, 1991; HAUG, 1991; QUINTOS, 1995; MARTIN 2000).

TREHAN and WALSH (1991) can be considered as the first contribution to unify both approaches. In particular, TREHAN and WALSH (1991) are the first explicitly to derive the conditions for fiscal deficit sustainability in terms of a relationship between the primary deficit (the deficit excluding interest payments on debt) and debt. In addition, HAKKIO and RUSH (1991) implicitly point to a relationship between the deficit and debt, although they concentrate on the cointegrating relationship between the components of the primary deficit. HAKKIO and RUSH (1991) postulate that if the total revenues and total expenditures are I(1) non-stationary variables that define the cointegrating relationship thus:

$$
R_{t}=\mu+\beta G_{t}+u_{t}
$$

with $0<\beta \leq 1$, then the condition that prevents a Ponzi game situation is satisfied. In this model, the value of $\beta$ in equation (8) determines the degree of sustainability. Thus, $0<\beta<1$ is associated with weak sustainability, whereas $\beta=1$ defines the sustainability in the strict sense (or strong sustainability). In economic terms, sustainability in the weak sense corresponds to a situation in which the government reacts to an increase in public debt, but this correction is not equal to the growth of public expenditure. In this case, an unsteady growing deficit and an increase in public debt can be observed. Consequently, HAKKIO and RUSH (1991) argue that a cointegrating relationship between $R_{t}$ and $G_{t}$ would be necessary for a strict interpretation of the sustainability of the deficit. However, QUINTOS (1995) indicates that $0<\beta \leq 1$ in equation (8) would be a 
necessary and sufficient condition for fiscal deficit sustainability, and the cointegrating relationship between $R_{t}$ and $G_{t}$ - regardless of whether or not the cointegration vector is imposed - would only be a sufficient condition for fiscal deficit sustainability. In this regard, the debt could be either I(1) or $\mathrm{I}(2)$ and the fiscal deficit sustainability would still hold, although the interpretation would be qualitatively different: in the event that the debt is $\mathrm{I}(1)$, there is strict sustainability, whereas if the debt is $\mathrm{I}(2)$, the sustainability will be weak.

QUINTOS (1995) remarks that although $0<\beta<1$ constitutes a necessary and sufficient condition for the sustainability of the public deficit, this is not consistent with the possibility that the government might market its debt in the long term. The fact that $0<\beta<1$ has important implications in terms of economic policy. If a government spends more than it raises, it will have a high risk of failure and will have to offer a higher interest rate to put its debt on the market. Another interesting aspect highlighted in QUINTOS (1995) is the different rate at which the fiscal deficit tends towards sustainability, which is determined by the order of integration of $B_{t}$ (see Theorem 1.1 in QUINTOS, 1995). Thus, the rate at which equation (7) tends to zero is higher if $B_{t} \sim I(1)$ than in the case that $B_{t} \sim I(2)$.

The main weakness of the proposal in QUINTOS (1995) is the way in which the test strategy is carried out. First, a consistent estimation of the parameter $\beta$ in equation (8) is required; second, it is necessary to test whether $0<\beta \leq 1$. In the case that the revenues and expenditures of the government are I(1) variables, estimating equation (8) can lead either to a spurious relationship (in which the estimated parameters are inconsistent), or to a cointegrating relationship (in which the estimated parameters are (super) consistent). On the one hand, in a spurious relationship, the value of $\beta$ cannot be identified by using estimation techniques based on individual analysis (country-by-country or region-by-region analysis) - this is the case in the empirical application in QUINTOS (1995), in which the sustainability of the US fiscal deficit is analysed. On the other hand, in the case that the model defines a cointegrating relationship, it is possible to obtain a consistent estimate of $\beta$, the statistical inference requiring the application of an efficient estimation method. Therefore, the main problem lies in the identification of the $\beta$ parameter in the possible case of no cointegration. As discussed below, this problem can be solved if the analysis is carried out using non-stationary panel data techniques.

\section{Sustainability of fiscal deficit and fiscal rules}

The strategy to test for fiscal deficit sustainability presented in the previous section has received some criticism in the literature, giving rise to alternative approaches. In this regard, BOHN (1998) proposes estimating a fiscal rule to assess the sustainability of the fiscal policy of the government. Basically, BOHN (1998) suggests checking whether there is a corrective response by the government to increases in the public debt. The focus is on the response from the primary surplus - non-financial revenues less non-financial expenditures (excluding interest payments on debt) - to changes in the level of the public debt. The model suggested in BOHN (1998) for the US economy takes the form:

$$
S_{t}=\rho B_{t}^{*}+\alpha Z_{t}+\varepsilon_{t},
$$

where the primary surplus is given by $S_{t}=R_{t}-G_{t}^{*}, G_{t}^{*}$ being the government spending excluding interest payments on debt, $B_{t}^{*}$ the level of debt in the economy at the beginning of period $t$ (which can be approximated by the level of debt in the period $t-1$ ) and finally, $Z_{t}$ being a vector of explanatory variables that capture the economic cycle. ${ }^{3}$ The sufficient condition for sustainability

\footnotetext{
${ }^{3}$ In fact, BOHN (1998) defines the primary surplus and debt at the beginning of the period divided by the GDP of the economy. This transformation has no influence on the interpretation of his model, so to be consistent with the
} 
requires $\rho>0$ in equation (9) so that the government would be taking corrective actions - reducing the level of expenditure (excluding interest on debt) and/or increasing tax revenues - to offset the changes in the level of debt. This approximation for assessing fiscal sustainability is known as the backward-looking approach, in which a positive response from the primary surplus to the debt of the economy is expected. It would be also possible to implement the forward-looking approach in CANZONERI et al. (2001), which expects that a change in the primary surplus causes a positive reaction of the future debt (for further details, see BAJO-RUBIO et al., 2009, 2014). This paper is based on the backward-looking approach in BOHN (1998).

The sign of $\rho$ in equation (9) provides an additional interpretation regarding the interaction between monetary and fiscal policies and its relation to the price level determination of the economies. As pointed out in BAJO-RUBIO et al. (2014), $\rho>0$ would indicate the prevalence of a monetary dominant regime, in which the monetary authority is expected to set the price level without constraint, whereas fiscal authority would adjust so that the budget surplus path would be endogenous. On the contrary, $\rho \leq 0$ would indicate the prevalence of a fiscal dominance regime, which assumes that fiscal authorities are able to set primary surpluses that follow an arbitrary process, not necessarily compatible with solvency. In this case, the budget surplus would be exogenous and the endogenous adjustment of the price level would be required to achieve fiscal solvency.

BOHN (1998) mentions that it is possible to proceed in two different ways. First, if the primary surplus and debt are I(1) non-stationary variables, one might consider the relationship:

$$
S_{t}=\rho B_{t}^{*}+v_{t}
$$

and test for the presence of cointegration between $S_{t}$ and $B_{t}^{*}$. If cointegration holds, that would mean that $v_{t}=\alpha Z_{t}+\varepsilon_{t}$ is an $\mathrm{I}(0)$ stationary process, so that, according to BOHN (1998), it would not be necessary explicitly to model the effect of the economic cycle on the primary surplus to obtain a consistent estimate of $\rho$. Second, if the primary surplus and debt are $\mathrm{I}(0)$ stationary variables, then equation (9) should be estimated with the inclusion of the cyclical determinants of the fiscal surplus to ensure a consistent estimate of $\rho$.

Beyond the specific case that is analysed in BOHN (1998), it might be that there is a link between the testing strategy that has been described in the previous section and Bohn's proposal. First, and in order to implement the approach in BOHN (1998), the order of integration of the variables needs to be known, something that is in itself the first way to check if the fiscal deficit is weakly or strongly sustainable. Therefore, a link between the two approaches can be established. Notwithstanding this, the relationship between the two approaches goes further.

Suppose that the fiscal variables involved in the model are I(1) non-stationary variables, so that equation (10) can be expressed as:

$$
\begin{aligned}
R_{t}-G_{t}^{*} & =\rho B_{t}^{*}+v_{t} \\
R_{t} & =G_{t}^{*}+\rho B_{t}^{*}+v_{t} .
\end{aligned}
$$

The comparison of equations (12) and (8) reveals that, apart from a constant term - which BOHN (1998) also included when estimating the model - there are, apparently, two differences. First, in equation (8) the total expenditure:

$$
G_{t}=G_{t}^{*}+r_{t} B_{t-1}
$$

is used, while in equation (12) a similar explanatory variable is used:

$$
\bar{G}_{t}=G_{t}^{*}+\rho B_{t-1}
$$

definition of the variables used so far, this paper uses variables in levels. As for the other explanatory variables $\left(Z_{t}\right)$, BOHN (1998) uses the variables GVAR and YVAR given in BARRO (1986), which aim to capture the temporary government spending and cyclical variations of the output of the economy, respectively. 
and, second, in equation (8) no restriction is imposed on $\beta$, while equation (12) imposes $\beta=1$. As can be seen, the main difference lies in the definition of the interest rate that is used; whereas equation (13) takes into account the interest rate for each period, equation (14) considers an average interest rate.

BOHN's (1998) model makes it possible to relate his sufficient conditions for fiscal deficit sustainability to those drawn from the approaches described in the previous section, which rely on cointegration analysis. Thus, BOHN (2007) indicates that, in the case that equation (12) represents a cointegrating relationship, three situations may occur:

- $\rho>r, r$ being the average interest rate of the debt, a situation that would imply $\mathrm{I}(0)$ stationarity of the deficit and debt;

- $0<\rho<r$, a situation that would cause slightly explosive behaviour of the deficit and debt, but with sufficiently slow growth to satisfy the intertemporal budget constraint;

- $\rho=r$, which implies that the debt would be an I(1) non-stationary process and the deficit an $\mathrm{I}(0)$ stationary process, fulfilling the intertemporal budget constraint as in QUINTOS (1995).

To sum up, BOHN's (1998) model can be seen as a special case of the approach based on the analysis of cointegration discussed in the previous section, where (i) the condition is imposed that the cointegration vector is known and equal to $(1,-1)^{\prime}$ and (ii) that the payment of debt interests is calculated using a constant interest rate - which can be defined as the average of the real interest rate. Given these features and as set forth in QUINTOS (1995), a particular definition of the necessary and sufficient conditions for the sustainability of the public deficit appears which requires that $r_{t}=\rho$. Finally, it should be noted that the model given by equation (10) relates a flow variable (primary surplus) and a stock variable (debt), both possibly being I(1) non-stationary variables. If so, this specification is related to the concept of multicointegration proposed by GRANGER and LEE (1989) and applied to the analysis of fiscal sustainability in BERENGUER-RICO and CARRION-I-SILVESTRE (2011), ESCARIO et al. (2012), and CAMARERO et al. (2015), among others.

\section{$5 \quad$ Data and descriptive analysis}

The main source of information used in this paper is the Spanish Ministry of Economy and Finance, which provides consolidated revenues and expenditures, settled by chapters, for the 17 Spanish ACs regions for the period 1984-2012. From the level breakdown at which the data are available, the non-financial revenues and expenditures of the ACs can be obtained, which allows computation of the deficit and primary surplus of the Spanish ACs. ${ }^{4}$ The debt of the Spanish ACs is taken from various issues of the Monthly Bulletin of the Bank of Spain, whereas the GDP deflator of each AC is obtained from the BDMORES database and the Regional Accounting of the Spanish National Statistical Institute (INE).

Figure A.1 presents the non-financial revenues and expenditures in real terms of the ACs, while Figure A.2 provides the debt and deficit. Finally, Figure A.3 depicts the evolution of the public debt, both in nominal and real terms. Figures A.1 to A.3 are provided in the online companion appendix. As can be seen, the overall debt of the ACs experienced sustained growth over the

\footnotetext{
${ }^{4}$ One might consider removing the two Spanish AC foral regions that have a funding system different from the other ACs, giving them greater autonomy in their decisions regarding raising and spending funds. However, these ACs also face the same conditions as the other ACs when assessing whether or not their fiscal policy is sustainable and it was thus decided to keep them in the sample.
} 
period analysed. There are, however, exceptions to this behaviour in some sub-periods. First, note that some ACs experienced a reduction in debt in real terms - Andalusia (2000-2008), the Basque Country and Navarre (1996-2007); in contrast, others saw a real deadlock in debt - the case of La Rioja in the period 1991-2008, Aragon, the Canary Islands, Catalonia, Galicia and Murcia in the period 1996-2008, and Madrid in 2003-2008. For the rest of the ACs, the debt increase was sustained throughout the period. Finally, it should be mentioned that this study covers the recent economic crisis, which affected the Spanish economy at the end of the period analysed. The short time period covered by the time series used and the occurrence of the economic crisis at the end of the period make it difficult to investigate the presence of structural instabilities, something that could be addressed in future research.

\section{Panel data integration and cointegration analyses}

Previous analyses in the literature have characterized the fiscal variables involved in the model specification described above as I(1) non-stationary processes, although it is possible that relationships among I(1) variables lead to consistent estimates of the parameters if the variables generate a cointegrating relationship. In this paper, the order of integration and cointegration analyses are performed using panel data techniques. The advantage of taking into account the statistical information from both the temporal and cross-sectional dimensions is the improvement in the statistical inference, given that panel data unit root and cointegration test statistics are supposed to be more powerful than those based on individual information. However, non-stationary panel data techniques can lead to misleading conclusions if the presence of cross-sectional dependence among the units of the panel data sets is not taken into account. The first generation of non-stationary panel data techniques assumed independence among the units of the panel data sets, an assumption that, if not satisfied, will introduce a bias to conclude in favour of the stationarity of the panel data (see BANERJEE et al. 2004, 2005). Although it is now common practice to apply panel data unit root and stationarity tests that account for cross-sectional dependence, few studies test whether such dependence exists. The application of these cross-sectional dependence tests can also provide some hints on the type of cross-sectional dependence that is present.

\subsection{Panel data cross-sectional dependence}

This section computes the test statistics in PESARAN $(2004,2014)$, henceforth, denoted as $W C D$ and $W C D_{L M}$ statistics, and the statistic in NG (2006), denoted as the svr statistic, testing the null hypothesis of cross-sectional independence against the alternative hypothesis of cross-sectional dependence using pair-wise Pearson correlation coefficients. The application of the test statistic in NG (2006) is also interesting because it provides information concerning the degree of dependence. Thus, NG (2006) proposes defining a group of small $(S)$ correlation coefficients and a group of large $(L)$ correlation coefficients, where $\vartheta$ denotes the proportion of correlation coefficients in the $S$ group. Once the sample of correlation coefficients has been split, the null hypothesis of no correlation in both sub-samples can be tested. If $\vartheta$ is large, it indicates that the dependence is pervasive.

Table A.1 presents the results of calculating the $W C D, W C D_{L M}$ and svr statistics for each panel data set. The qualitative conclusion that can be drawn is that the $W C D$ test clearly rejects the null hypothesis of no correlation - this conclusion is supported by the $W C D_{L M}$ test statistic. The large values of these statistics can be taken as an indication that strong cross-sectional dependence is affecting the units of the panel data. This can be confirmed by computing the degree

of cross-sectional dependence as in BAILEY et al. (2012). As can be seen, the point estimate $\delta$ 
is close to one for the two variables for which it can be computed, although the $90 \%$ confidence interval defined by $\left(\stackrel{\circ}{\delta}_{L}, \stackrel{\circ}{\delta}_{U}\right)$ gives a wide range of values for this parameter.

The svr statistic in NG (2006) shows that the null hypothesis of no correlation cannot be rejected at the $5 \%$ significance level for the small sub-sample of correlations for all variables (see the p-values associated with the $\operatorname{svr}(S)$ statistic), while it is clearly rejected when analysing the sub-sample of large correlations (see the results for the $\operatorname{svr}(L)$ statistic). It should also be noted that the $L$ group is considerably more numerous than the $S$ group, which indicates that (i) there is evidence of strong cross-sectional correlation and (ii) that the correlation is pervasive (see NG, 2006). When all correlations are considered, the null hypothesis of cross-sectional independence is clearly rejected for all variables. It should be mentioned that the pervasiveness of the cross-sectional dependence suggests that panel data unit root and cointegration test statistics can capture the cross-sectional dependence by defining common factor models, as suggested by BAI and NG (2004).

\subsection{Panel data order of integration analysis}

Given the conclusions obtained above, panel data unit root test statistics that incorporate unobservable common factors to capture the cross-sectional dependence are computed. BAI and NG (2004), MOON and PERRON (2004) and PESARAN (2007) provide three of the proposals available in the literature that include the use of common factors when testing the order of integration. ${ }^{5}$ Table A.2 provides the results of the two test statistics proposed in PESARAN (2007) - denoted as CIPS and CIPS* - for different values of the order of the autoregressive correction $(p)$ used when estimating the ADF auxiliary regression equations. In general, the results lead to the non-rejection of the null hypothesis of panel data unit root at the $5 \%$ significance level, regardless of the order of the autoregressive correction; there is only one exception as the null hypothesis of unit root is not rejected for the primary surplus with $p=0$. Therefore, it can be concluded that there is strong evidence that the variables considered are I(1) non-stationarity processes. Table A.2 also includes the results of the test statistics proposed by MOON and PERRON (2004), denoted by $t_{a}$ and $t_{b}$. The evidence drawn from these statistics depends on the variable and the number of common factors $(r)$. On the one hand, in general the null hypothesis of panel data unit root cannot be rejected at a significance level of $5 \%$ for the revenues, except when $r=1$ and the $t_{b}$ statistic is used, or for the debt and the deficit. On the other hand, the null hypothesis of unit root is clearly rejected for the primary surplus, regardless of the number of common factors and test statistic that is used. Finally, the results for the expenditures are mixed as the null hypothesis of unit root cannot be rejected when $r \leq 4$, but it is rejected for $r=5$ and $r=6 .{ }^{6}$ Consequently, the evidence obtained from these two test statistics is not as clear-cut as that obtained with Pesaran's statistics, although in most cases it is possible to conclude that the variables are $\mathrm{I}(1)$.

The evidence obtained with the Pesaran and Moon-Perron test statistics may be biased because of the assumption that the dynamic of the common factors is the same as that driving the idiosyncratic disturbance term. This limitation is overcome by the proposal in BAI and NG (2004), which analyses the order of integration of the common factors and the idiosyncratic disturbance terms

\footnotetext{
${ }^{5}$ As noted by BAI and NG (2009), the proposals in MOON and PERRON (2004) and PESARAN (2007) control the presence of cross-sectional dependence allowing for common factors, although the common factors and idiosyncratic shocks are restricted to have the same order of integration. Therefore, it is not possible to cover situations in which one component (e.g. the common factors) is $\mathrm{I}(0)$ and the other component (for example, the idiosyncratic shocks) is I(1), and vice versa. In practical terms, it transpires that the test statistics in MOON and PERRON (2004) and PESARAN (2007) are statistical procedures that provide statistical inference only on the idiosyncratic shocks, where the dynamics of both the idiosyncratic and the common components are restricted to be the same.

${ }^{6}$ The use of the different information criteria in BAI and NG (2002) always leads to selecting the maximum number of common factors that is specified.
} 
separately. Table A.2 reports on the test statistics proposed in BAI and NG (2004). The conclusion obtained from these statistics is that all variables present symptoms of being I(1) non-stationary stochastic processes as in all cases the presence of I(1) non-stationary common factors is detected, i.e. $\hat{r}_{1}>0 .{ }^{7}$ Therefore, and regardless of the stochastic properties of the idiosyncratic disturbance terms, all variables are I(1) non-stationary panel data sets.

\subsection{Panel data cointegration}

This section computes the panel cointegration test statistics taken from BANERJEE and CARRIONI-SILVESTRE (2011, 2014), WESTERLUND (2008) and BAI and CARRION-I-SILVESTRE (2013) as these account for the presence of cross-sectional dependence among the units of the panel data through the specification of an approximate common factor model. ${ }^{8}$ This paper applies the two alternative approaches to analyse the sustainability of fiscal policy discussed above. The first strategy requires testing the presence of cointegration in the model given by equation (8):

$$
R_{t}=\mu+\beta G_{t}+u_{t}
$$

The second alternative is defined in BOHN (1998) and is based on the estimation of the fiscal rule given by equation (10):

$$
S_{t}=\mu+\rho B_{t}^{*}+v_{t} .
$$

To estimate equation (16), BOHN (1998) considers that the level of debt at the beginning of period $t$ is proxied by the level of debt in period $t-1$.

\subsubsection{Relationship between revenues and expenditures}

Table A.3 shows that the procedure designed by BANERJEE and CARRION-I-SILVESTRE (2015) detects the presence of an $\mathrm{I}(1)$ non-stationary common factor $\left(\hat{r}_{1}=1\right)$ that drives the cross-sectional dependence of the panel data model. ${ }^{9}$ As for the panel cointegration, the ADF test applied to the idiosyncratic disturbance terms leads to rejection of the null hypothesis of no panel cointegration at the $5 \%$ significance level. Consequently, there is evidence for a long-term relationship (cointegration) between the revenues and expenditures once the cross-sectional dependence has been taken into account. This conclusion is also achieved with the application of the $C A D F p$ test statistic, delivering a parameter estimate of $\hat{\beta}=0.8727$ in equation (8) - it is worth mentioning that regardless of the presence of panel cointegration, this estimation is a consistent estimate of the relationship between revenues and expenditures.

Turning to the DH test statistics from WESTERLUND (2008), the conclusions depend on the degree of homogeneity that is assumed. While the test statistic that allows for heterogeneity in the

\footnotetext{
${ }^{7}$ As above, the use of different information criteria to estimate the number of common factors always leads to choosing the maximum number of common factors specified.

${ }^{8} \mathrm{It}$ is worth mentioning that there are some important features that are common to and distinguish these proposals. First, one important difference concerns the order of integration of the common factors as WESTERLUND (2008) considers that all common factors are $\mathrm{I}(0)$ stationary, whereas the other approaches assume that there might be a combination of $\mathrm{I}(0)$ and I(1), as in BAI and NG (2004). Second, BAI and CARRION-I-SILVESTRE (2013) consider the most general case, in which the common factors might both affect the dependent variable and the stochastic regressors, whereas the other proposals assume that the common factors and the stochastic regressors are orthogonal. Finally, in BANERJEE and CARRION-I-SILVESTRE (2011), the effect of the unobserved common factors is taken into account, as in PESARAN (2006) who uses cross-sectional averages to proxy the common factors. The other proposals estimate the common factors using principal components, as in BAI and NG (2004).

${ }^{9}$ The total number of common factors is denoted by $r$. The number of $\mathrm{I}(1)$ non-stationary common factors is denoted by $r_{1}$, whereas the number of $\mathrm{I}(0)$ stationary common factors is $r_{0}$, so that $r=r_{0}+r_{1}$.
} 
autoregressive coefficient $\left(D H_{g}\right)$ leads to rejection of the null hypothesis of no panel cointegration, the statistic that imposes homogeneity $\left(D H_{p}\right)$ does not reject the null hypothesis when 3 to 5 common factors are specified. The contradiction between these two test statistics and the results obtained with the other two procedures may indicate that the assumption of homogeneity when testing for the presence of cointegration is not advisable.

The application of the test statistic from BAI and CARRION-I-SILVESTRE (2013) reinforces the presence of a cointegrating relationship between revenues and expenditures, regardless of the number of common factors (see Table A.4). As can be seen, the estimated $\beta$ parameter in equation (8) is around one, with values ranging from 0.943 to 1.005 depending on the number of common factors.

\subsubsection{Relationship between primary surplus and debt}

In this case, the panel data cointegration test statistics derived from BANERJEE and CARRION-ISILVESTRE $(2011,2015)$ and WESTERLUND (2008) indicate that there is cointegration between the primary surplus and the debt. This conclusion is reinforced when computing the test statistics given in BAI and CARRION-I-SILVESTRE (2013) as in general the null hypothesis of no panel data cointegration is clearly rejected by the $P_{m}$ and $P$ statistics - the exception being when 4 common factors are specified - and for the $M S B_{\xi}$ statistic if 1,5 or 6 common factors are considered. These results indicate that there is a long-run relationship between the primary surplus and the debt.

It should be noted that regardless of the presence of cointegration, using the common correlated effects (CCE) estimator from BANERJEE and CARRION-I-SILVESTRE (2011) provides a consistent estimate of the $\rho$ parameter which measures the relationship between the primary surplus and the debt. Table A.3 shows that $\hat{\rho}=0.1742$ (sustainability is met, in terms of Bohn's requirements), whereas the estimates in Table A.4 depend on the number of common factors allowed, ranging between -0.073 (no sustainability, in terms of Bohn's definition) and 0.143 (sustainability is met).

\subsection{Estimation of the panel cointegration relationships: Fiscal deficit sustain- ability analysis}

This section presents the estimated cointegrating relationships of the two approaches used to determine the sustainability of the fiscal policy of the Spanish ACs. Due to the presence of cross-sectional dependence, the procedures for estimating the cointegrating relationships used here are those proposed in BAI et al. (2009) and KAPETANIOS et al. (2011). The approach of BAI et al. (2009) estimates the cointegration vector using procedures that render consistent and efficient estimates of the parameters - continuous updated fully-modified (CUP-FM) and continuous updated bias corrected (CUP-BC) estimators - considering the presence of $\mathrm{I}(0)$ and/or I(1) common factors. ${ }^{10}$ The strategy in KAPETANIOS et al. (2011) is based on the CCE approach in PESARAN (2006). ${ }^{11}$

Table A.5 reports the results of the estimates for the two models and the three estimators. Regarding the cointegrating relationship between the revenues and expenditures, it can be seen that the parameter estimates are positive and statistically significant. The coefficient estimated using the CCE estimation procedure is somewhat below 1 (0.873), whereas the estimates using the

\footnotetext{
${ }^{10}$ Given the efficiency property of these estimators, a statistical inference on the estimated parameters can be performed - at the limit, the estimated parameters are distributed according to normal distribution.

${ }^{11}$ These authors show that in panel cointegration, the pooled CCE estimator is a consistent estimator of the cointegration vector, which is asymptotically distributed as a normal distribution. There is an important feature that distinguishes both proposals. Thus, whereas KAPETANIOS et al. (2011) assume that the stochastic regressors are weakly exogenous, BAI et al. (2009) specify a more general framework in which the stochastic regressors might be endogenous.
} 
optimal estimation procedure in BAI et al. (2009) are placed around 1. In this regard, the null hypothesis that the parameter is equal to 1 is rejected at the $5 \%$ significance level for all estimates, although the interpretation is qualitatively different. Thus, whereas the CEE estimate is smaller than 1 (weak sustainability), note that the estimate using the CUP-FM and CUP-BC estimators is slightly larger than 1, which leads to fiscal surpluses - the fiscal deficit is sustainable in the strict sense (strong sustainability).

The second part of Table A.5 collects the results of the estimation of BOHN's (1998) model. The estimated parameters are greater than zero and statistically significant, so that the sufficient condition of sustainability advocated by BOHN (1998) is met. It is worth noticing that the CCE estimate is quite large compared to the other ones, something that can be explained by the efficient estimation property of the estimates in BAI et al. (2009). The estimates indicate that for every 100 euros increasing the debt of the Spanish ACs, the primary surplus increases by 6.8 euros (CUP-FM) and 5 euros (CUP-BC), which is consistent with a reaction that satisfies the intertemporal budget constraint.

It is interesting to note that the average interest rate of the debt for the period analysed and for all the Spanish ACs is $r=0.07$, a value that is in accordance with the efficient estimate of $\rho$. Therefore, the null hypothesis that $\rho=r=0.07$ cannot be rejected when using the CUP-FM estimate; in this case, the value of the test statistic is $(0.068-0.07) / 0.005=-0.4$, a value that is smaller than the critical value at the $5 \%$ level of significance of a standard normal distribution, whereas it is rejected using the CUP-BC estimate - in this case, $(0.05-0.07) / 0.005=-4$. Following BOHN (2007), these results indicate that the IBC is satisfied.

In summary, the different approaches that have been followed in this paper have led to the conclusion that the fiscal policy of the Spanish ACs is sustainable in the sense that in the long term the IBC is met and in addition, that the primary surplus reacts positively and significantly to changes in the level of debt of the ACs.

\subsection{Estimation of the individual cointegrating relationships: Fiscal deficit sus- tainability analysis}

To gain an insight into the heterogeneous degree of the fiscal sustainability across the Spanish ACs, the analysis proceeds with the estimation of a single equation of the error correction model (ECM) specification for each region. The estimation assumes that there is cointegration among the variables involved in the two specifications that have been investigated, accounting for the common factors that have been estimated. The model specified for the revenues and expenditures relationship is given by:

$\Delta R_{i, t}=\sum_{j=0}^{k_{i}} \phi_{i, j} \Delta G_{i, t-j}+\sum_{j=0}^{k_{i}} \Delta F_{t-j}^{\prime} \gamma_{i, j}+\sum_{j=1}^{k_{i}} \alpha_{i, j} \Delta R_{i, t-j}+\lambda_{i}\left[R_{i, t-1}-\mu_{i}-\beta_{i} G_{i, t-1}-F_{t-1}^{\prime} \pi_{i}\right]+\varepsilon_{i, t}$,

where the number of lags $\left(k_{i}\right)$ is chosen using the Bayesian information criterion (BIC), with a maximum of three lags, $i=1, \ldots, 17$; a similar equation is specified for the primary surplus and debt relationship. The estimation of the common factors is based on the CUP-BC estimation procedure, although the results are robust to the use of the CUP-FM estimates. Table A.6 reports the $\hat{\beta}_{i}$ parameter for each AC, showing that these individual estimates are close to 1 . This picture is consistent with the CUP-BC panel estimate that has been obtained. The lower estimate for $\beta_{i}$ is for the Balearic Islands, which is closely followed by Castilla-La Mancha, although even in these cases the estimate is larger than 0.9. Therefore, we can conclude that the degree of fiscal deficit sustainability across the Spanish ACs is quite homogeneous. Table A.6 also reports the DOLS 
efficient estimate for $\beta_{i}$ obtained from the estimation of:

$$
R_{i, t}=\mu_{i}+\beta_{i} G_{i, t}+F_{t}^{\prime} \pi_{i}+\sum_{j=-k_{i}}^{k_{i}} \delta_{i, j} \Delta G_{i, t-j}+\sum_{j=-k_{i}}^{k_{i}} \Delta F_{t-j}^{\prime} \zeta_{i, j}+u_{i, t}
$$

considering a maximum of two lags and leads $\left(k_{i}=2\right)$ - the number of lags and leads is selected for each region using the BIC. Only in six out of seventeen cases - the Balearic Islands, Castilla-La Mancha, Castilla and León, Catalonia and La Rioja - is the null hypothesis that $\beta_{i}=1$ is rejected against the alternative hypothesis that $\beta_{i}<1$, i.e. ACs for which weak fiscal sustainability is found; as above, even in these cases, the estimate is larger than 0.9. There is, however, some regional heterogeneity in the speed of adjustment to long-run disequilibria as the estimates for the $\lambda_{i}$ parameter in equation (17) range from - 0.368 (Valencia) to -1.752 (Castilla and León) - note that all $\hat{\lambda}_{i}$ show the expected negative sign and are statistically significant.

As for the primary surplus and debt relationship, Table A.7 shows that the degree of heterogeneity in the estimation of $\rho$ from the ECM specification is higher, finding six estimates with a negative sign - Castilla-La Mancha, the Balearic Islands, Castilla and León, La Rioja, Murcia and Asturias. As before, Table A.7 shows that all $\lambda_{i}$ estimates have the expected negative sign and are statistically significant. The DOLS estimates of the long-run relationship reveal that in eight out of seventeen cases, $\hat{\rho}_{i}$ is statistically significant, being positive in six cases - Andalusia, Castilla and León, Catalonia, Galicia, Madrid and the Basc Country - and negative in two cases - Valencia and Navarre. ${ }^{12}$ Thus, for nine out of seventeen ACs, $\hat{\rho}_{i}$ is not statistically significant. This picture differs from that drawn using the pooled estimate of $\rho$ and indicates that although the fiscal deficit is sustainable according to Bohn's definition from an aggregated point of view, there is heterogeneous behaviour across the Spanish ACs.

The analysis conducted in this section aims to giving a glimpse into the heterogeneous behaviour of the Spanish ACs in terms of fiscal deficit sustainability. The approximation which draws on the revenues and expenditures relationship points to sustainability, something that is in accordance with the evidence drawn from the pooled estimators. The evidence in favour of sustainability is weaker if we focus on the primary surplus and debt relationship. Thus, and contrary to what has been found using the panel estimation, for most ACs this relationship is not statistically significant. Although this might appear contradictory, it should be borne in mind that Bohn's approach imposes some parameter constraints that might not be met when focusing on the individual estimation of the model.

\section{Conclusions}

This paper analyses the sustainability of the deficit of the Spanish ACs in the period 1984-2012 using real revenues, expenditures and debt. The literature on the sustainability of public deficit is divided into two major approaches. First, there are those that are based on the cointegration analysis of the fiscal variables. Second, there are those based on fiscal rules which relate the primary surplus to the level of debt of the economies. Both approaches have been presented in this paper, discussing the similarities and differences that characterize them in order to draw a robust conclusion on the question of the sustainability of fiscal policy.

A first set of results clearly shows that the variables involved in both approaches share the characteristics of being I(1) non-stationary variables and being affected by the presence strong cross-sectional dependence. The cross-sectional dependence has been captured through the use

\footnotetext{
${ }^{12}$ As mentioned above, $\rho_{i} \leq 0$ indicates the prevalence of a fiscal dominance regime.
} 
of parsimonious common factor models, which are able to account for global stochastic trends. This just makes it clear that the system of financing of the ACs and the competences that they have undertaken are driven by the same legal framework that gives rise to this strong (pervasive) cross-sectional dependence.

A second important result has been to evidence how the deficit of the Spanish ACs as a whole is sustainable in the long-run, regardless of the analytical approach chosen. The paper has also shown that the fiscal rule that relates the primary surplus and debt levels at the beginning of the period has also proved to define a cointegrating relationship, with a parameter of interest that is similar to the average interest rate of the debt of the period analysed. This implies that both approaches lead to the same conclusion, namely that the fiscal deficit of the ACs in Spain is sustainable for the period analysed.

Finally, the paper focuses on the individual estimation of the different model specifications to assess the degree of heterogeneity of the fiscal sustainability of the Spanish ACs. Whereas the results obtained from the individual estimation of the revenue and expenditure relationship agree with the panel data analysis, heterogeneous conclusions have been obtained when focusing on the estimation of the primary surplus and debt relationship.

Acknowledgement 1 The author acknowledges the financial support from the IEA2011 grant from the Institut d'Estudis Autonòmics, Department of Institutional Relations and Participation of the Government of Catalonia, and from the Spanish Ministerio de Ciencia e Innovacion under grant ECO2014-58991-C3-1-R.

\section{References}

[1] AFONSO, A. (2005) Fiscal sustainability: the unpleasant European case, FinanzArchiv 61, $19-44$.

[2] BAI, J. and CARRION-I-SILVESTRE, J.L. (2013) Testing panel cointegration with unobservable dynamic common factors that are correlated with the regressors, Econometrics Journal $16,222-249$.

[3] BAI, J., KAO, C. and NG, S. (2009) Panel cointegration with global stochastic trends, Journal of Econometrics 149, 82-99.

[4] BAI, J. and NG, S. (2004) A PANIC attack on unit roots and cointegration, Econometrica 72, 1127-1177.

[5] BAJO-RUBIO, O., DÍAZ-ROLDÁN, C. and ESTEVE, V. (2009) Deficit sustainability and inflation in EMU: an analysis from the fiscal theory of the price level, European Journal of Political Economy 25, 525-539.

[6] BAJO-RUBio, O., DÍAZ-ROLDÁN, C. and ESTEVE, V. (2014) Deficit sustainability, and monetary versus fiscal dominance: the case of Spain, 1850-2000, Journal of Politicy Modeling 36, 924-937.

[7] BANERJEE, A. and CARRION-I-SILVESTRE, J. L. (2011) Testing for panel cointegration using common correlated effects estimators. Working paper, Universitat de Barcelona.

[8] BANERJEE, A. and CARRION-I-SILVESTRE, J. L. (2015) Cointegration in panel data with breaks and cross-Section dependence, Journal of Applied Econometrics 30, 1-23. 
[9] BANERJEE, A., MARCELlino, M. and OSBAT, C. (2004) Some cautions on the use of panel methods for integrated series of macro-economic data, Econometrics Journal 7, 322-340.

[10] BANERJEE, A., MARCELlinO, M. and OSBAT, C. (2005) Testing for PPP: should we use panel methods?, Empirical Economics 30, 77-91.

[11] BARRO, R. (1986) U.S. deficits since World War I, Scandinavian Journal of Economics 88, 195-222.

[12] BERENGUER-RICO, V. and CARRION-I-SILVESTRE, J. L. (2011) Regime shifts in stockflow I(2)- I(1) systems: the case of US fiscal sustainability, Journal of Applied Econometrics $26,298-321$.

[13] BOHN, H. (1998) The behavior of U.S. public debt and deficits, The Quarterly Journal of Economics 13, 949-963.

[14] BOHN, H. (2005) The sustainability of fiscal policy in the United States, Tech. Rep. 1446, CESifo, Munchen.

[15] BOHN, H. (2007) Are stationarity and cointegration restrictions really necessary for the intertemporal budget constraint?, Journal of Monetary Economics 54, 1837-1847.

[16] CAMARERO, M., CARRION-I-SILVESTRE, J. L. and TAMARIT, C. (2015) The relationship between debt level and fiscal sustainability in OECD countries: a multicointegration approach, Economic Inquiry 53, 129-149.

[17] CANZONERI, M. B., CUMBY, R. E. and DIBA, B. T. (2001) Is the price level determined by the needs of fiscal solvency?, American Economic Review 91, 1221-1238.

[18] ESCARIO, R., GADEA, M. and SABATÉ, M. (2012) Multicointegration, seignorage and fiscal sustainability. Spain 1857-2000, Journal of Policy Modeling 34, 270-283.

[19] ESTELLER, A. and SOLÉ, A. (2004) Estabilidad presupuestaria y financiación autonómica, Hacienda Pública Española, monografia 2004, 173-201.

[20] GRANGER, C. W. J. and LEE, T. (1989) Multicointegration. Advances in Econometrics, 8, 71-84.

[21] HAKKIO, C. and RUSH, M. (1991) Is the budget deficit too large?, Economic Inquiry 24, 429-445.

[22] HAMILTON, J. and FLAVIN, M. (1986) On the limitations of government borrowing: A framework for empirical testing, American Economic Review 76, 808-816.

[23] HAUG, A. (1991) Cointegration and government borrowing constraints: Evidence for the U.S, Journal of Business \& Economic Statistics 9, 97-101.

[24] KAPETANIOS, G., PESARAN, M. H. and YAMAGATA, T. (2011) Panels with nonstationary mul- tifactor error structures, Journal of Econometrics 160, 326-348.

[25] MARTIN, G. (2000) U.S. deficit sustainability: A new approach based on multiple endogeneous breaks, Journal of Applied Econometrics 15, 83-105. 
[26] MOON, H. R. and PERRON, B. (2004) Testing for unit root in panels with dynamic factors, Journal of Econometrics 122, 81-126.

[27] NG, S. (2006) Testing cross-section correlation in panel data using spacings, Journal of Business and Economic Statistics 24, 12-23.

[28] PESARAN, M. H. (2004) General diagnostic tests for cross section dependence in panels. CESifo Working Papers. No. 1233.

[29] PESARAN, M. H. (2006) Estimation and inference in large heterogeneous panels with a multifactor error structure, Econometrica 74, 967-1012.

[30] PESARAN, M. H. (2007) A simple panel unit root test in the presence of cross section dependence, Journal of Applied Econometrics 22, 265-312.

[31] PESARAN, M. H. (2014) Testing weak cross-sectional dependence in large panels, Econometric Reviews, forthcoming.

[32] PHILLIPS, P. C. B. and MOON, H. R. (1999) Linear regression limit theory for nonstationary panel data, Econometrica 67, 1057-1111.

[33] QUINTOS, C. E. (1995) Sustainability of the deficit process with structural shifts, Journal of Business \& Economic Statistics 13, 409-418.

[34] TREHAN, B. and WALSH, C. (1988) Common trends, the government budget constraint, and revenue smoothing, Journal of Economic Dynamics and Control 12, 425-444.

[35] TREHAN, B. and WALSH, C. (1991) Testing intertemporal budget constraints: Theory and applications to U.S. federal budget and current account deficits, Journal of Money, Credit and Banking 23, 206-223.

[36] WESTERLUND, J. (2008) Panel cointegration tests of the Fisher effect, Journal of Applied Econometrics 23, 193-233.

[37] WESTERLUND, J., MAHDAVI, S. and FIROOZI, F. (2011) The tax-spending nexus: evidence from a panel of US State-local governments, Economic Modelling 28, 885-890.

[38] WILCOX, D. (1989) The sustainability of government deficits: Implications of the present value borrowing constraint, Journal of Money, Credit and Banking 54, 1837-1847. 


\title{
Companion appendix: Fiscal deficit sustainability of the Spanish regions
}

\author{
Josep Lluís Carrion-i-Silvestre
}

AQR-IREA research group

Department of Econometrics, Statistics and Spanish Economy

University of Barcelona

Av. Diagonal, 690, 08034 Barcelona.

Tel: 934024598, Fax: 934021821

Email: carrion@ub.edu

May 8, 2015 


\section{A Appendix}

Tables and figures that are mentioned in the paper that will appear in the online appendix of the published paper. 


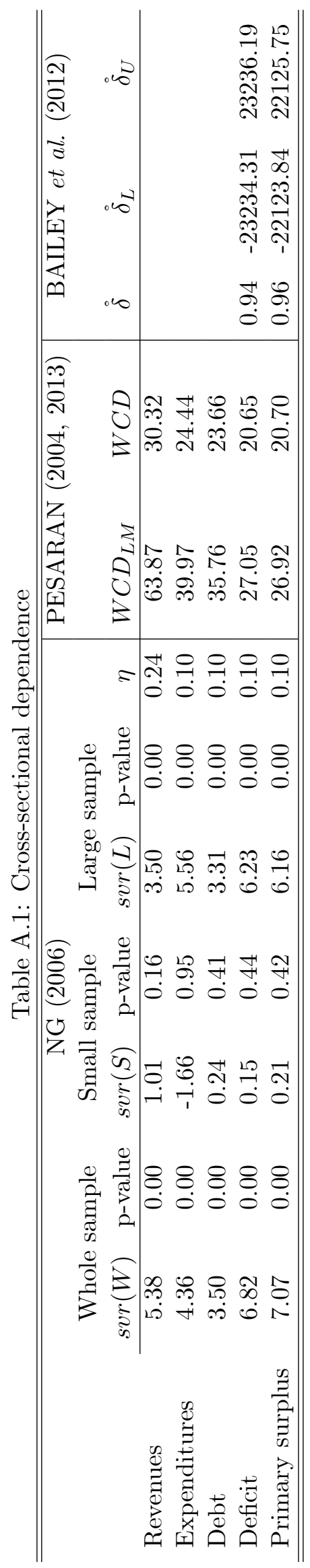




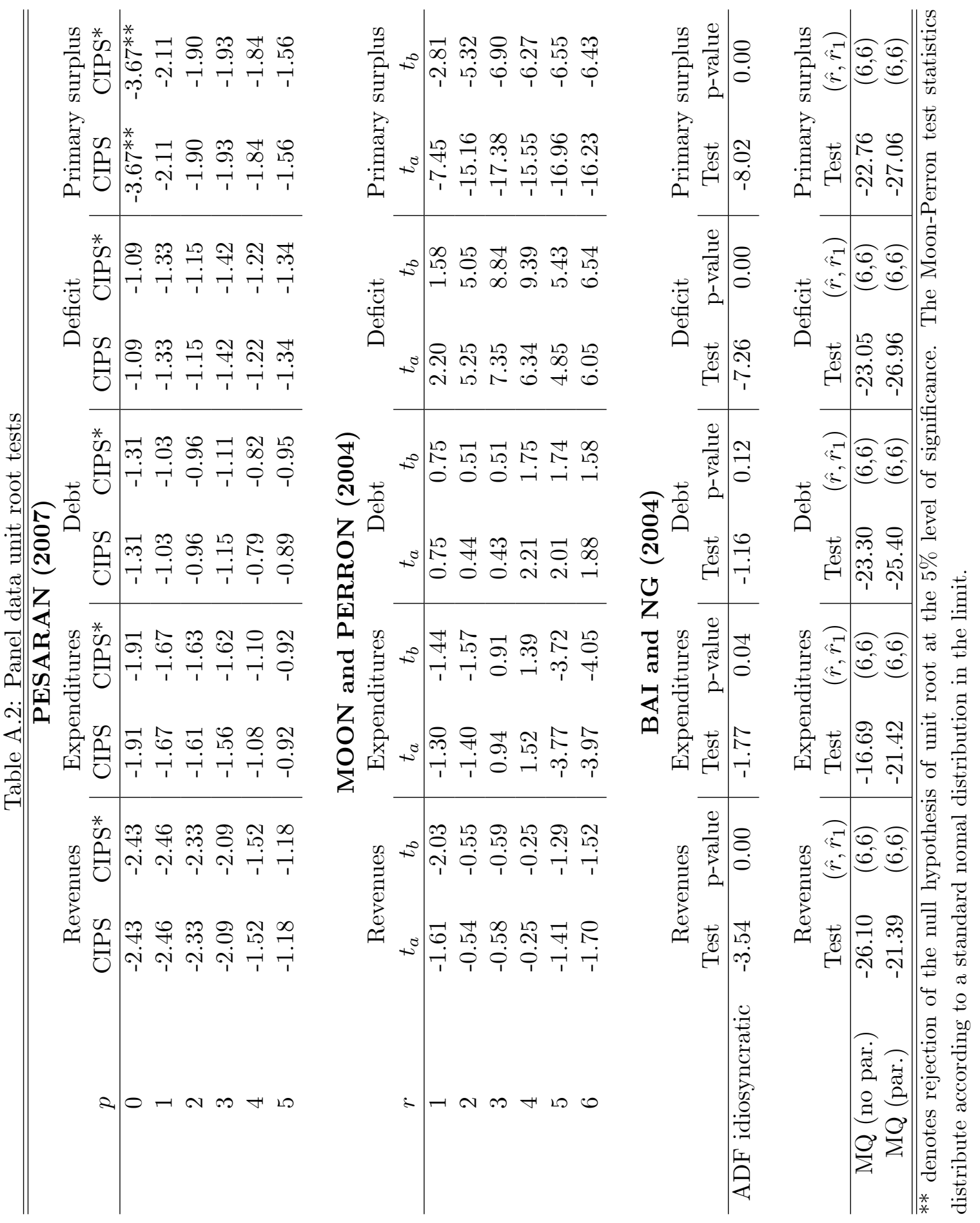


Table A.3: BANERJEE AND CARRION-I-SILVESTRE $(2011,2014)$ and WESTERLUND(2008) panel cointegration test statistics

\section{BANERJEE and CARRION-I-SILVESTRE (2015)}

Revenues and expenditures

Primary deficit and debt

\begin{tabular}{|c|c|c|c|c|c|c|}
\hline \multirow{3}{*}{ ADF-idio } & Test & \multicolumn{2}{|c|}{ p-value } & Test & \multicolumn{2}{|c|}{$\mathrm{p}$-value } \\
\hline & -2.47 & 0.00 & & -2.67 & 0.00 & \\
\hline & Test & $\hat{r}_{1}$ & $\hat{r}$ & & $\hat{r}_{1}$ & $\hat{r}$ \\
\hline MQ (no par.) & -4.58 & 1 & 1 & -4.13 & 1 & 2 \\
\hline MQ (par.) & -2.33 & 1 & 1 & -20.85 & 2 & 2 \\
\hline
\end{tabular}

BANERJEE and CARRION-I-SILVESTRE (2011)

Revenues and expenditures Primary deficit and debt

\begin{tabular}{lcc|cc} 
& Test & $\hat{\beta}$ & Test & $\hat{\rho}$ \\
\cline { 2 - 5 }$C A D F p$ & $-4.00^{* *}$ & 0.8727 & $-3.97^{* *}$ & 0.1742
\end{tabular}

\section{WESTERLUND (2008)}

Revenues and expenditures Primary deficit and debt

\begin{tabular}{ccccc|cccc}
$r$ & $D H_{g}$ & $\mathrm{p}$-value & $D H_{p}$ & $\mathrm{p}$-value & $D H_{g}$ & $\mathrm{p}$-value & $D H_{p}$ & $\mathrm{p}$-value \\
\hline 1 & 82.04 & 0.00 & 4.87 & 0.00 & 9.73 & 0.00 & 13.87 & 0.00 \\
2 & 7.63 & 0.00 & 1.99 & 0.02 & 9.76 & 0.00 & 3.33 & 0.00 \\
3 & 6.23 & 0.00 & 0.23 & 0.41 & 16.14 & 0.00 & 3.43 & 0.00 \\
4 & 11.45 & 0.00 & 0.56 & 0.29 & 14.09 & 0.00 & 2.98 & 0.00 \\
5 & 16.29 & 0.00 & -0.09 & 0.54 & 9.49 & 0.00 & 5.14 & 0.00 \\
6 & 7.06 & 0.00 & 4.72 & 0.00 & 16.13 & 0.00 & 6.53 & 0.00 \\
\hline \hline
\end{tabular}

Table A.4: BAI and CARRION-I-SILVESTRE (2013) panel cointegration test statistics

\begin{tabular}{cccccccc}
\hline \hline \multicolumn{7}{c}{ Revenues and expenditures } \\
$r$ & $M S B_{\xi}$ & $\mathrm{p}$-value & $P_{m}$ & $\mathrm{p}$-value & $P$ & $\mathrm{p}$-value & $\hat{\beta}$ \\
\hline 1 & -2.678 & 0.004 & 7.781 & 0.000 & 98.163 & 0.000 & 1.005 \\
2 & -2.755 & 0.003 & 7.293 & 0.000 & 94.143 & 0.000 & 0.979 \\
3 & -2.815 & 0.002 & 6.033 & 0.000 & 83.753 & 0.000 & 0.955 \\
4 & -2.762 & 0.003 & 5.698 & 0.000 & 80.990 & 0.000 & 0.943 \\
5 & -2.626 & 0.004 & 5.642 & 0.000 & 80.521 & 0.000 & 0.970 \\
6 & -2.453 & 0.007 & 4.263 & 0.000 & 69.150 & 0.000 & 0.947
\end{tabular}

Primary surplus and debt

\begin{tabular}{cccccccc}
$r$ & $M S B_{\xi}$ & $\mathrm{p}$-value & $P_{m}$ & $\mathrm{p}$-value & $P$ & $\mathrm{p}$-value & $\hat{\rho}$ \\
\hline 1 & -1.507 & 0.066 & 3.322 & 0.000 & 61.396 & 0.003 & -0.073 \\
2 & -0.989 & 0.161 & 3.204 & 0.001 & 60.423 & 0.003 & 0.142 \\
3 & -0.192 & 0.424 & 1.266 & 0.103 & 44.438 & 0.108 & 0.112 \\
4 & -0.791 & 0.214 & -0.208 & 0.582 & 32.288 & 0.552 & 0.143 \\
5 & -1.726 & 0.042 & 1.962 & 0.025 & 50.175 & 0.036 & 0.111 \\
6 & -2.046 & 0.020 & 2.518 & 0.006 & 54.761 & 0.013 & 0.117 \\
\hline \hline
\end{tabular}


Table A.5: Panel data cointegrating vector estimates

\begin{tabular}{|c|c|c|c|c|}
\hline \multicolumn{5}{|c|}{ Revenues and expenditures } \\
\hline & $\mathrm{CCE}$ & CUP-FM & CUP-BC & $\hat{r}$ \\
\hline$\beta$ & 0.873 & 1.012 & 1.011 & 1 \\
\hline s.e. & 0.051 & 0.005 & 0.005 & \\
\hline t-ratio $(\beta=0)$ & 17.118 & 210.005 & 210.209 & \\
\hline t-ratio $(\beta=1)$ & -2.490 & 2.549 & 2.241 & \\
\hline \multicolumn{5}{|c|}{ Primary surplus and debt } \\
\hline & $\mathrm{CCE}$ & CUP-FM & CUP-BC & $\hat{r}$ \\
\hline$\rho$ & 0.174 & 0.068 & 0.050 & 2 \\
\hline s.e. & 0.056 & 0.005 & 0.005 & \\
\hline t-ratio $(\rho=0)$ & 3.135 & 12.793 & 9.596 & \\
\hline
\end{tabular}


Table A.6: Estimation of a single equation Error Correction Model for the revenues and expenditures relationship. CUP-BC estimation based results

\begin{tabular}{|c|c|c|c|c|c|c|c|c|c|c|c|}
\hline \multirow{3}{*}{ AND } & \multicolumn{8}{|c|}{ ECM estimation } & \multicolumn{3}{|c|}{ DOLS estimation of $\beta_{i}$} \\
\hline & $\hat{\phi}_{i, 0}$ & $\hat{\gamma}_{i, 0}$ & $\hat{\alpha}_{i, 1}$ & $\hat{\phi}_{i, 1}$ & $\hat{\gamma}_{i, 1}$ & $\hat{\lambda}_{i}$ & $\hat{\beta}_{i}$ & $\hat{\pi}_{i}$ & $\hat{\beta}_{i}$ & $t_{\beta_{i}=0}$ & $t_{\beta_{i}=1}$ \\
\hline & $\begin{array}{c}0.91 \\
(15.12)\end{array}$ & $\begin{array}{l}-1.79 \\
(-5.99)\end{array}$ & & & & $\begin{array}{c}-1.17 \\
(-5.56)\end{array}$ & 1.05 & -2.13 & 1.05 & 97.29 & 4.99 \\
\hline ARA & $\begin{array}{c}0.92 \\
(21.05)\end{array}$ & $\begin{array}{l}-0.28 \\
(-5.14)\end{array}$ & & & & $\begin{array}{l}-0.73 \\
(-3.69)\end{array}$ & 0.98 & -0.33 & 0.98 & 106.33 & -1.81 \\
\hline $\mathrm{AST}$ & $\begin{array}{c}0.95 \\
(25.51)\end{array}$ & $\begin{array}{c}-0.13 \\
(-3.19)\end{array}$ & & & & $\begin{array}{l}-0.66 \\
(-4.31)\end{array}$ & 1.01 & -0.22 & 1.01 & 100.76 & 0.70 \\
\hline BAL & $\begin{array}{c}0.81 \\
(6.60)\end{array}$ & $\begin{array}{l}-0.41 \\
(-3.77)\end{array}$ & & & & $\begin{array}{l}-1.10 \\
(-4.97)\end{array}$ & 0.92 & -0.34 & 0.80 & 38.25 & -9.68 \\
\hline CAN & $\begin{array}{c}1.01 \\
(17.66)\end{array}$ & $\begin{array}{l}-0.40 \\
(-4.94)\end{array}$ & & & & $\begin{array}{l}-1.26 \\
(-6.28)\end{array}$ & 1.00 & -0.34 & 1.00 & 95.87 & 0.13 \\
\hline CANT & $\begin{array}{c}0.81 \\
(8.45)\end{array}$ & $\begin{array}{l}-0.10 \\
(-1.56)\end{array}$ & & & & $\begin{array}{l}-0.61 \\
(-3.17)\end{array}$ & 0.97 & -0.15 & 0.98 & 29.01 & -0.60 \\
\hline CYL & $\begin{array}{c}0.99 \\
(26.80)\end{array}$ & $\begin{array}{l}-0.19 \\
(-2.12)\end{array}$ & & & & $\begin{array}{l}-1.75 \\
(-9.62)\end{array}$ & 0.99 & -0.57 & 0.98 & 187.84 & -3.86 \\
\hline CLM & $\begin{array}{c}0.72 \\
(10.19)\end{array}$ & $\begin{array}{l}-0.51 \\
(-2.83)\end{array}$ & $\begin{array}{c}0.34 \\
(1.18)\end{array}$ & $\begin{array}{l}-0.03 \\
(-0.13)\end{array}$ & $\begin{array}{c}0.12 \\
(0.35)\end{array}$ & $\begin{array}{l}-1.28 \\
(-3.88)\end{array}$ & 0.93 & -0.82 & 0.94 & 80.06 & -5.53 \\
\hline CAT & $\begin{array}{c}0.87 \\
(12.22)\end{array}$ & $\begin{array}{l}-2.75 \\
(-7.15)\end{array}$ & & & & $\begin{array}{l}-0.93 \\
(-3.82)\end{array}$ & 0.97 & -2.37 & 0.97 & 107.99 & -2.96 \\
\hline VAL & $\begin{array}{c}0.92 \\
(9.05)\end{array}$ & $\begin{array}{l}-1.01 \\
(-3.44)\end{array}$ & & & & $\begin{array}{c}-0.37 \\
(-1.92)\end{array}$ & 1.00 & -1.47 & 0.96 & 30.17 & -1.23 \\
\hline EXT & $\begin{array}{c}0.89 \\
(16.57)\end{array}$ & $\begin{array}{l}-0.20 \\
(-3.14)\end{array}$ & & & & $\begin{array}{c}-0.92 \\
(-5.02)\end{array}$ & 1.00 & -0.29 & 1.01 & 104.33 & 0.96 \\
\hline GAL & $\begin{array}{c}0.92 \\
(17.94)\end{array}$ & $\begin{array}{l}-0.31 \\
(-2.75)\end{array}$ & & & & $\begin{array}{l}-0.46 \\
(-3.03)\end{array}$ & 1.02 & -0.42 & 0.99 & 127.93 & -0.92 \\
\hline MAD & $\begin{array}{c}0.87 \\
(13.06)\end{array}$ & $\begin{array}{l}-0.79 \\
(-2.90)\end{array}$ & & & & $\begin{array}{l}-1.50 \\
(-6.86)\end{array}$ & 1.04 & -0.99 & 1.06 & 127.86 & 7.08 \\
\hline MUR & $\begin{array}{c}0.82 \\
(7.92)\end{array}$ & $\begin{array}{l}-0.45 \\
(-4.11)\end{array}$ & & & & $\begin{array}{l}-1.28 \\
(-5.77)\end{array}$ & 0.99 & -0.47 & 1.04 & 78.65 & 2.72 \\
\hline NAV & $\begin{array}{c}1.51 \\
(11.34)\end{array}$ & $\begin{array}{c}-0.37 \\
(-3.59)\end{array}$ & $\begin{array}{c}0.07 \\
(0.44)\end{array}$ & $\begin{array}{c}-0.64 \\
(-3.61)\end{array}$ & $\begin{array}{c}0.24 \\
(2.09)\end{array}$ & $\begin{array}{l}-0.69 \\
(-3.25)\end{array}$ & 1.01 & -0.25 & 1.00 & 28.99 & 0.09 \\
\hline BASC & $\begin{array}{c}0.83 \\
(4.78)\end{array}$ & $\begin{array}{l}-1.30 \\
(-4.64)\end{array}$ & & & & $\begin{array}{l}-0.73 \\
(-3.55)\end{array}$ & 1.05 & -1.04 & 1.04 & 26.40 & 1.05 \\
\hline RIO & $\begin{array}{c}0.94 \\
(10.22)\end{array}$ & $\begin{array}{l}-0.06 \\
(-2.40)\end{array}$ & & & & $\begin{array}{l}-1.15 \\
(-5.43)\end{array}$ & 0.95 & -0.04 & 0.95 & 57.61 & -2.89 \\
\hline
\end{tabular}


Table A.7: Estimation of a single equation Error Correction Model for the primary surplus and debt relationship. CUP-BC estimation based results

\begin{tabular}{|c|c|c|c|c|c|c|c|c|c|}
\hline \multirow{3}{*}{ AND } & \multicolumn{7}{|c|}{ ECM estimation } & \multicolumn{2}{|c|}{ DOLS estimation of $\hat{\rho}_{i}$} \\
\hline & $\hat{\phi}_{i, 0}$ & $\hat{\gamma}_{i, 1,0}$ & $\hat{\gamma}_{i, 2,0}$ & $\hat{\lambda}_{i}$ & $\hat{\rho}_{i}$ & $\hat{\pi}_{i, 1}$ & $\hat{\pi}_{i, 2}$ & $\hat{\rho}_{i}$ & $t_{\rho_{i}=0}$ \\
\hline & $\begin{array}{c}0.10 \\
(3.12)\end{array}$ & $\begin{array}{c}-1.98 \\
(-19.74)\end{array}$ & $\begin{array}{c}2.23 \\
(21.18)\end{array}$ & $\begin{array}{l}-1.48 \\
(-7.91)\end{array}$ & 0.10 & -1.98 & 2.20 & 0.11 & 24.07 \\
\hline ARA & $\begin{array}{c}-0.03 \\
(-0.40)\end{array}$ & $\begin{array}{c}-0.29 \\
(-4.98)\end{array}$ & $\begin{array}{l}-0.13 \\
(-2.25)\end{array}$ & $\begin{array}{c}-0.83 \\
(-3.78)\end{array}$ & 0.01 & -0.32 & -0.07 & -0.01 & -0.20 \\
\hline $\mathrm{AST}$ & $\begin{array}{l}-0.12 \\
(-1.73)\end{array}$ & $\begin{array}{l}-0.13 \\
(-3.10)\end{array}$ & $\begin{array}{c}0.00 \\
(0.03)\end{array}$ & $\begin{array}{l}-0.70 \\
(-3.55)\end{array}$ & -0.01 & -0.19 & 0.10 & 0.03 & 0.61 \\
\hline BAL & $\begin{array}{c}0.06 \\
(0.50)\end{array}$ & $\begin{array}{l}-0.51 \\
(-4.11)\end{array}$ & $\begin{array}{c}0.06 \\
(0.51)\end{array}$ & $\begin{array}{l}-1.13 \\
(-4.81)\end{array}$ & -0.05 & -0.29 & -0.03 & -0.04 & -0.72 \\
\hline CAN & $\begin{array}{c}0.13 \\
(1.54)\end{array}$ & $\begin{array}{l}-0.45 \\
(-5.54)\end{array}$ & $\begin{array}{c}0.13 \\
(1.54)\end{array}$ & $\begin{array}{c}-1.12 \\
(-5.19)\end{array}$ & 0.06 & -0.34 & 0.16 & 0.00 & 0.10 \\
\hline CANT & $\begin{array}{l}-0.01 \\
(-0.04)\end{array}$ & $\begin{array}{l}-0.14 \\
(-2.13)\end{array}$ & $\begin{array}{c}0.14 \\
(2.04)\end{array}$ & $\begin{array}{c}-0.60 \\
(-2.83)\end{array}$ & 0.08 & -0.19 & 0.09 & 0.18 & 1.80 \\
\hline CYL & $\begin{array}{l}-0.03 \\
(-0.37)\end{array}$ & $\begin{array}{l}-0.38 \\
(-3.29)\end{array}$ & $\begin{array}{c}0.48 \\
(3.57)\end{array}$ & $\begin{array}{l}-1.05 \\
(-4.46)\end{array}$ & -0.04 & -0.47 & 0.39 & 0.34 & 12.67 \\
\hline CLM & $\begin{array}{l}-0.19 \\
(-2.72)\end{array}$ & $\begin{array}{c}-0.63 \\
(-4.02)\end{array}$ & $\begin{array}{c}-1.62 \\
(-11.59)\end{array}$ & $\begin{array}{c}-0.57 \\
(-2.33)\end{array}$ & -0.06 & -0.76 & -1.20 & -0.11 & -1.75 \\
\hline CAT & $\begin{array}{c}0.06 \\
(9.73)\end{array}$ & $\begin{array}{c}-2.77 \\
(-36.11)\end{array}$ & $\begin{array}{c}-2.14 \\
(-30.88)\end{array}$ & $\begin{array}{l}-0.51 \\
(-2.63)\end{array}$ & 0.05 & -2.72 & -2.36 & 0.06 & 17.37 \\
\hline VAL & $\begin{array}{l}-0.08 \\
(-1.42)\end{array}$ & $\begin{array}{c}-1.01 \\
(-4.23)\end{array}$ & $\begin{array}{c}0.89 \\
(4.21)\end{array}$ & $\begin{array}{l}-0.53 \\
(-2.68)\end{array}$ & 0.00 & -1.25 & 1.35 & -0.06 & -3.26 \\
\hline EXT & $\begin{array}{l}-0.16 \\
(-1.46)\end{array}$ & $\begin{array}{l}-0.19 \\
(-2.83)\end{array}$ & $\begin{array}{l}-0.14 \\
(-2.07)\end{array}$ & $\begin{array}{l}-0.84 \\
(-4.20)\end{array}$ & 0.03 & -0.28 & -0.02 & 0.02 & 0.46 \\
\hline GAL & $\begin{array}{l}-0.02 \\
(-0.31)\end{array}$ & $\begin{array}{l}-0.36 \\
(-4.05)\end{array}$ & $\begin{array}{c}0.24 \\
(2.54)\end{array}$ & $\begin{array}{c}-0.70 \\
(-3.84)\end{array}$ & 0.09 & -0.46 & 0.33 & 0.11 & 13.18 \\
\hline MAD & $\begin{array}{c}0.09 \\
(1.99)\end{array}$ & $\begin{array}{l}-1.05 \\
(-6.49)\end{array}$ & $\begin{array}{c}1.93 \\
(12.10)\end{array}$ & $\begin{array}{c}-1.10 \\
(-5.06)\end{array}$ & 0.04 & -0.81 & 1.81 & 0.08 & 7.93 \\
\hline MUR & $\begin{array}{c}0.07 \\
(0.57)\end{array}$ & $\begin{array}{c}-0.63 \\
(-6.08)\end{array}$ & $\begin{array}{c}0.46 \\
(4.72)\end{array}$ & $\begin{array}{c}-1.36 \\
(-6.17)\end{array}$ & -0.02 & -0.44 & 0.34 & -0.04 & -1.02 \\
\hline NAV & $\begin{array}{c}0.08 \\
(0.47)\end{array}$ & $\begin{array}{l}-0.30 \\
(-2.39)\end{array}$ & $\begin{array}{l}-0.08 \\
(-0.57)\end{array}$ & $\begin{array}{c}-0.70 \\
(-3.17)\end{array}$ & 0.14 & -0.29 & -0.02 & -0.22 & -32.72 \\
\hline BASC & $\begin{array}{c}0.25 \\
(2.24)\end{array}$ & $\begin{array}{l}-1.27 \\
(-5.37)\end{array}$ & $\begin{array}{c}-0.34 \\
(-1.50)\end{array}$ & $\begin{array}{l}-0.70 \\
(-3.08)\end{array}$ & 0.21 & -1.10 & -0.13 & 0.08 & 2.64 \\
\hline RIO & $\begin{array}{c}0.24 \\
(1.61)\end{array}$ & $\begin{array}{l}-0.09 \\
(-2.80)\end{array}$ & $\begin{array}{c}0.07 \\
(1.88)\end{array}$ & $\begin{array}{c}-0.65 \\
(-2.35)\end{array}$ & -0.03 & -0.04 & -0.00 & -0.05 & -0.83 \\
\hline
\end{tabular}



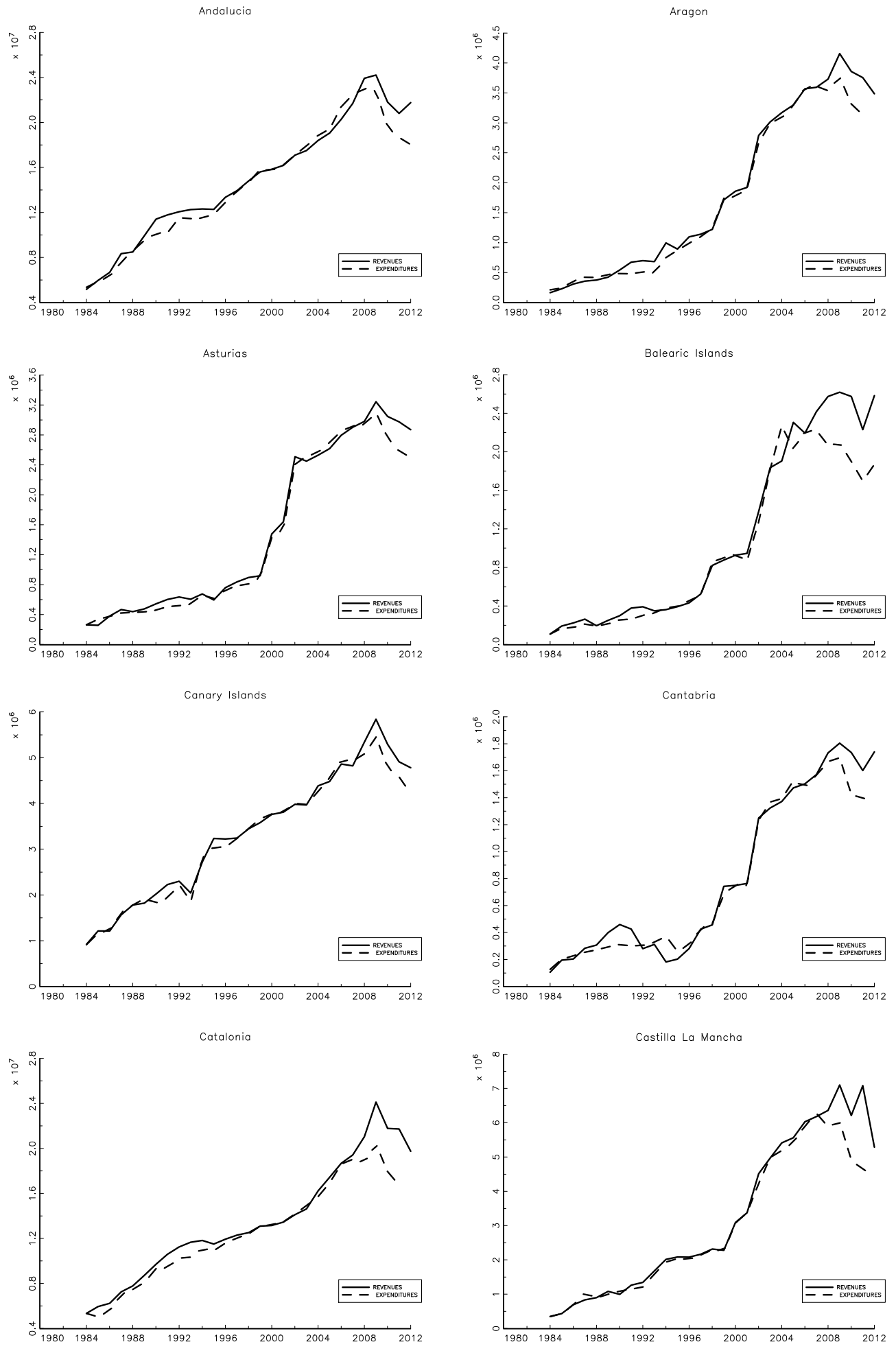

Figure A.1. Revenues and expenditures of the Spanish ACs 

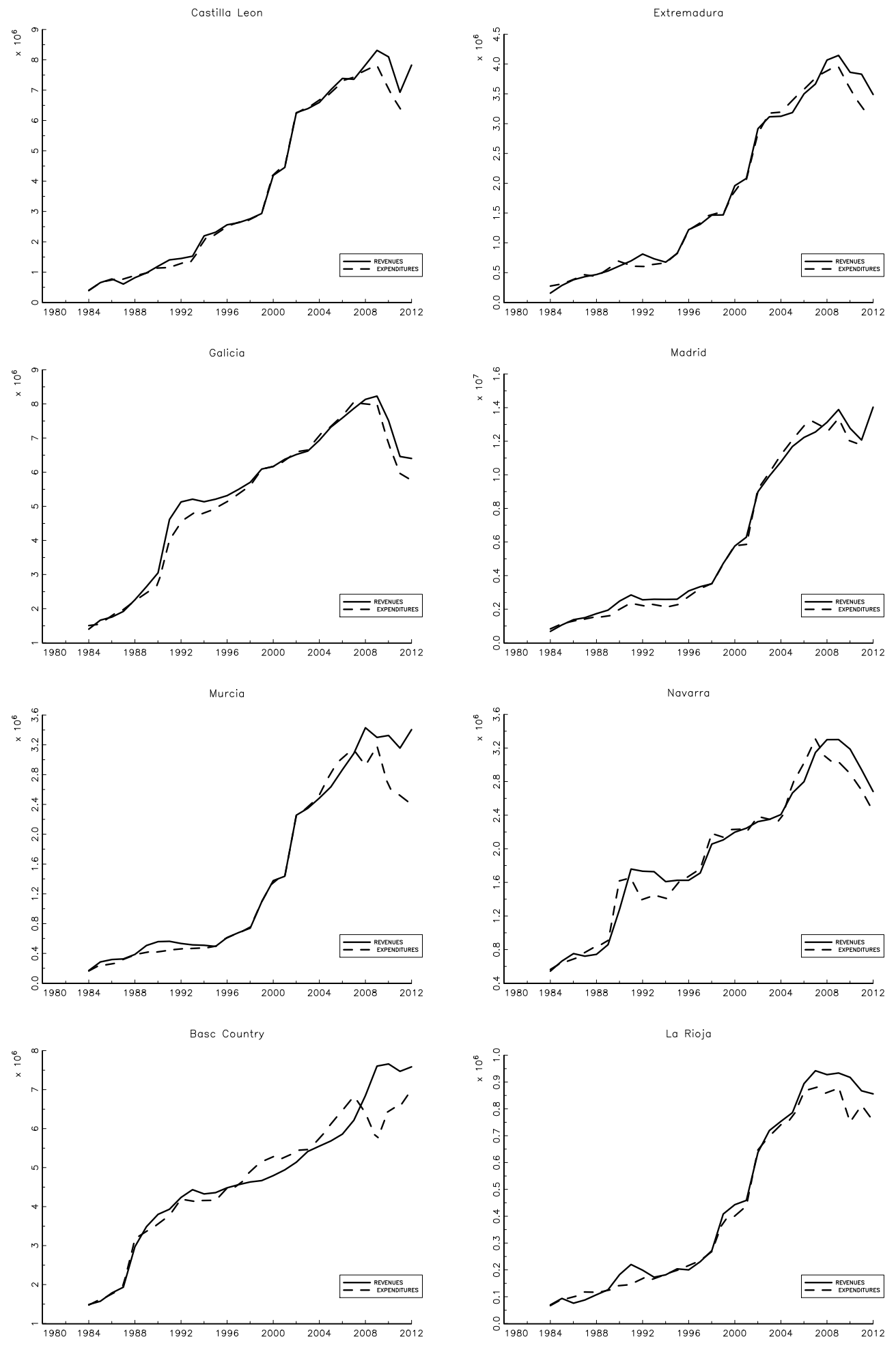

Figure A.1 (Cont). Revenues and expenditures of the Spanish ACs 


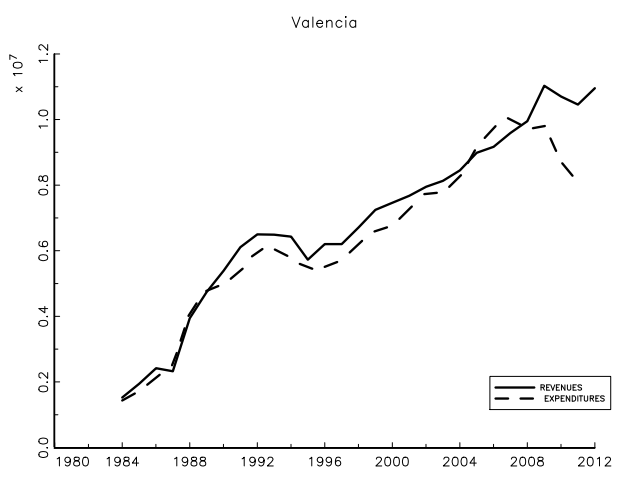

Figure A.1 (Cont). Revenues and expenditures of the Spanish ACs 

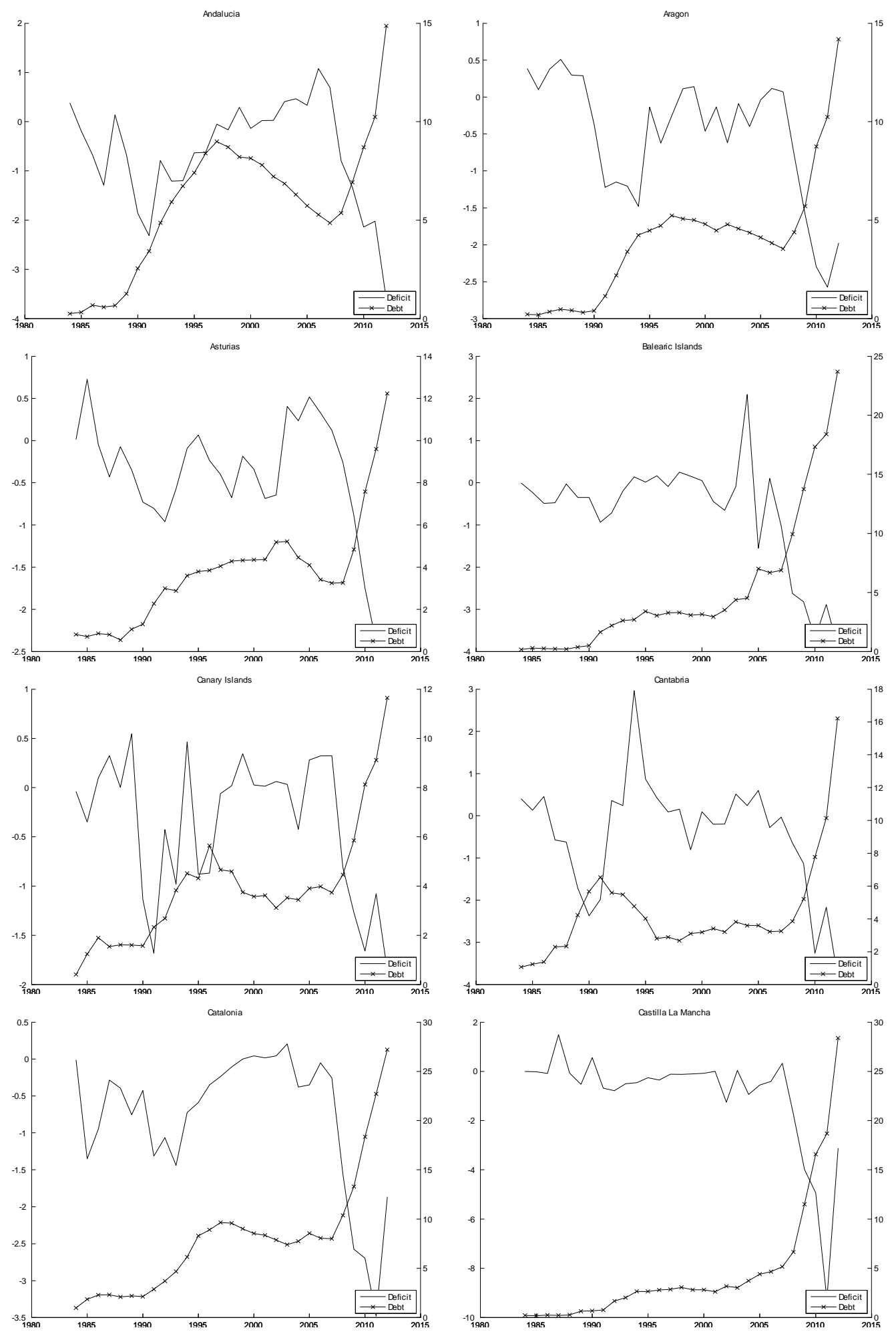

Figure A.2. Deficit (left) and debt (right) over GDP ratios of the Spanish ACs 

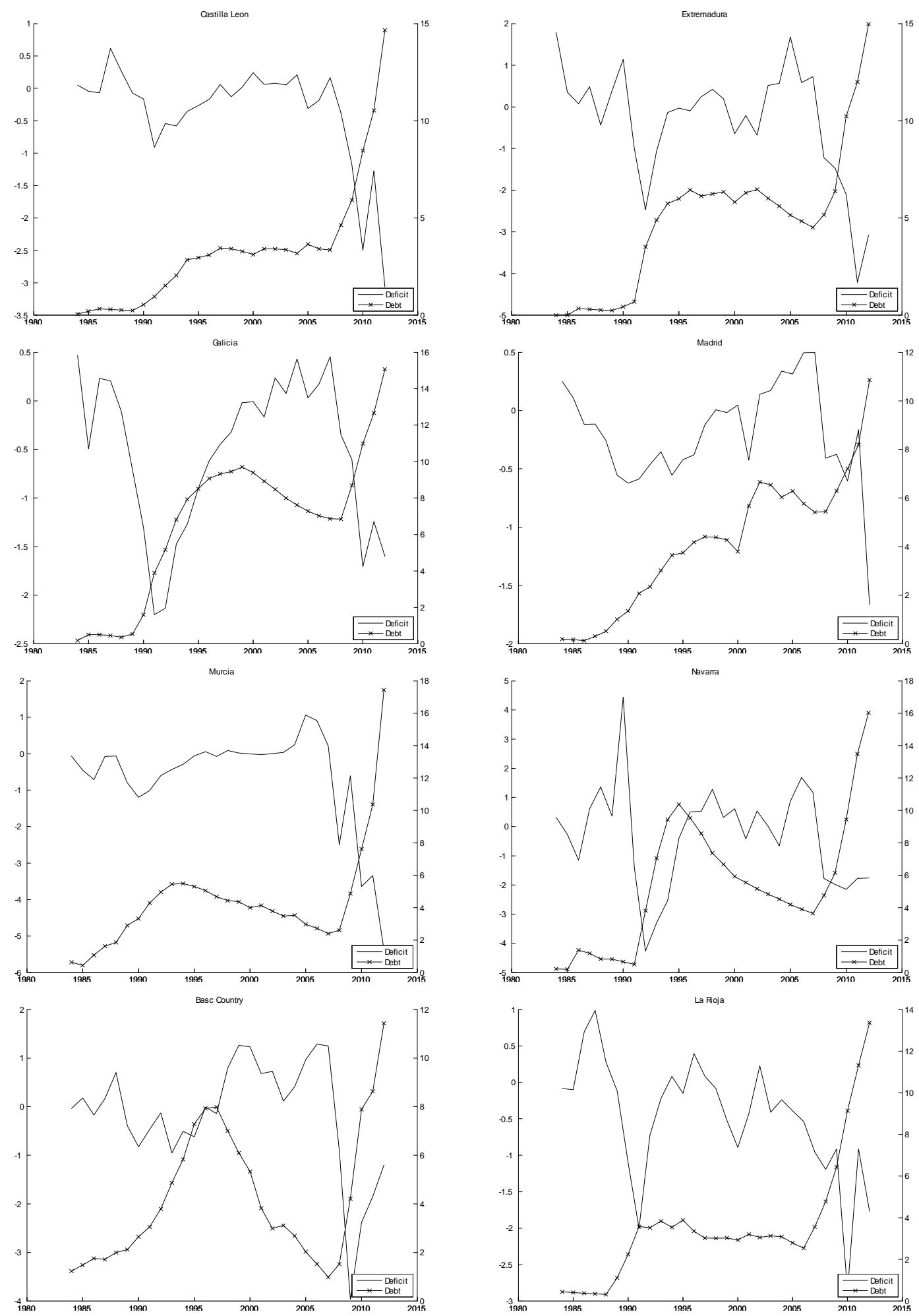

Figure A.2 (Cont). Deficit (left) and debt (right) over GDP ratios of the Spanish ACs 


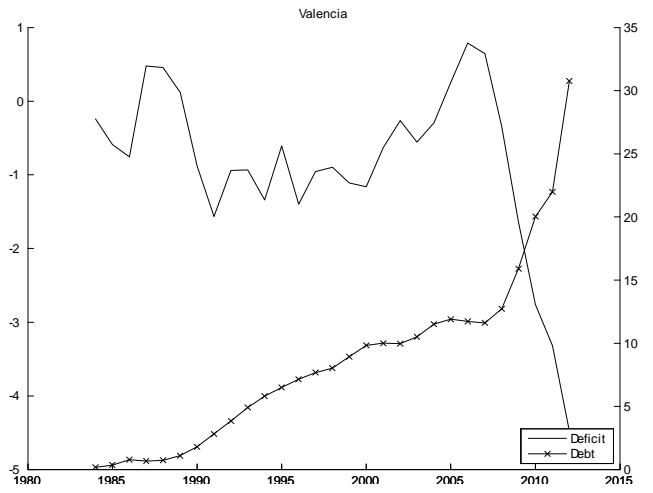

Figure A.2 (Cont). Deficit (left) and debt (right) over GDP ratios of the Spanish ACs 

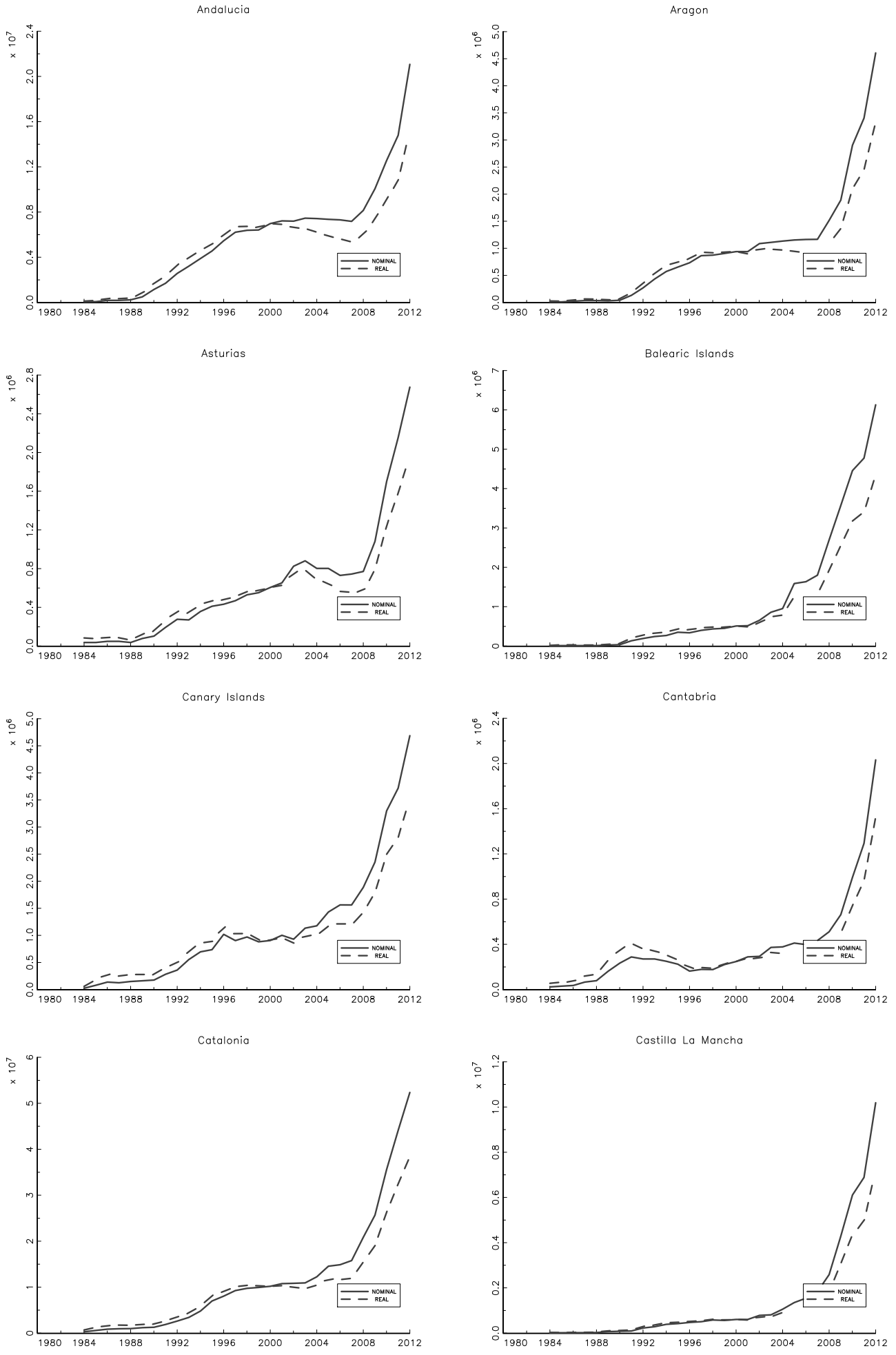

Figure A.3. Debt in nominal and real terms 

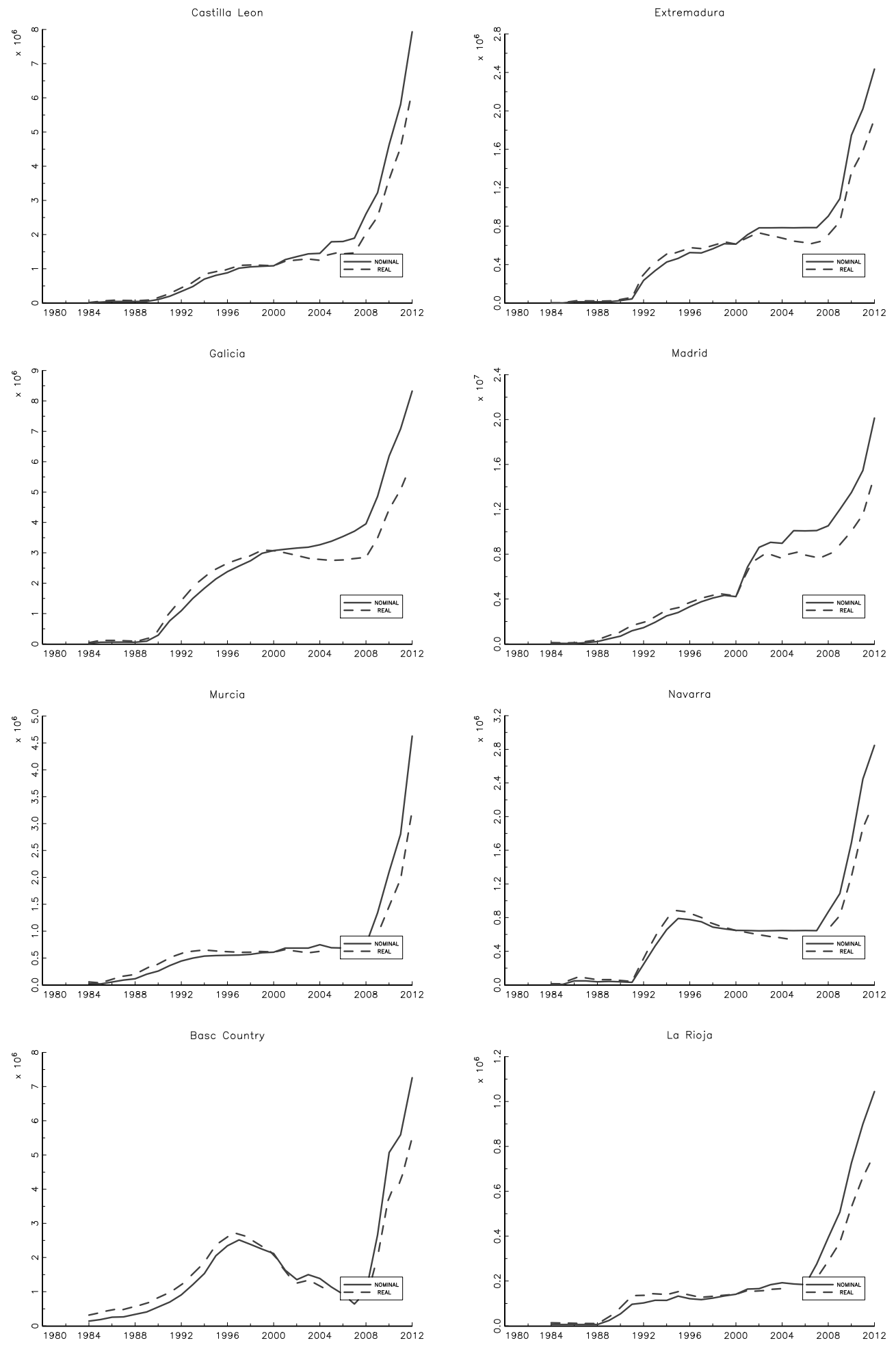

Figure A.3 (Cont). Debt in nominal and real terms 


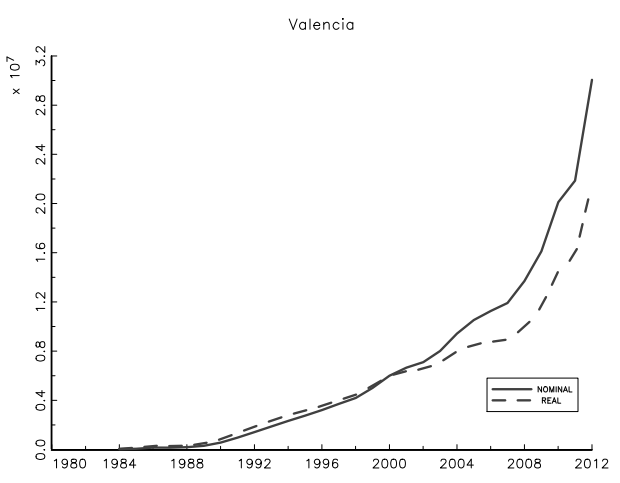

Figure A.3 (Cont). Debt in nominal and real terms 